\title{
UHPLC-MS-based metabolomics and chemoinformatics study reveals the neuroprotective effect and chemical characteristic in Parkinson's disease mice after oral administration of Wen-Shen-Yang-Gan decoction
}

\author{
Guoxue Zhu ${ }^{1,3,{ }^{*}}$, Wang Wang ${ }^{2, *}$, Chang Chen ${ }^{1,4}$, Lili Tang ${ }^{1}$, Yan Liang ${ }^{1}$, Zhennian Zhang ${ }^{1}$, Yan Lu $^{1}$, \\ Yang Zhao ${ }^{1, \&}$ \\ ${ }^{1}$ Department of Neurology, Nanjing Hospital of Chinese Medicine Affiliated to Nanjing University of Chinese \\ Medicine, Nanjing University of Chinese Medicine, Nanjing, Jiangsu, China \\ ${ }^{2}$ School of Medicine and Holistic Integrative Medicine, Nanjing University of Chinese Medicine, Nanjing, Jiangsu, \\ China \\ ${ }^{3}$ Chinese Medicine Modernization and Big Data Research Center, Nanjing Hospital of Chinese Medicine Affiliated \\ to Nanjing University of Chinese Medicine, Nanjing University of Chinese Medicine, Nanjing, Jiangsu, China \\ ${ }^{4}$ Medical School of Nanjing University, Nanjing, Jiangsu, China \\ *Equal contribution
}

Correspondence to: Yang Zhao; email: yangzhaotcm2018@163.com, https://orcid.org/0000-0002-8843-9397

Keywords: Parkinson's disease, Wen-Shen-Yang-Gan decoction, DA neurons apoptosis, UPLC-Q-TOF-MS, multivariate statistical analysis

Received: January 9, 2021

Accepted: July 6, 2021

Published: August 2, 2021

Copyright: (C) 2021 Zhu et al. This is an open access article distributed under the terms of the Creative Commons Attribution License (CC BY 3.0), which permits unrestricted use, distribution, and reproduction in any medium, provided the original author and source are credited.

\section{ABSTRACT}

Parkinson's disease (PD), the typical neurodegenerative disease, is characterized by the progressive loss of dopaminergic neurons in the substantia nigra (SN). However, no therapeutic agent used currently could slow down neuronal cell loss so as to decelerate or halt the progression of PD. Traditional Chinese medicine (TCM) has been utilized to treat the dysfunction of the autonomic nervous system. Wen-Shen-Yang-Gan decoction (WSYGD) has a good effect on the clinical treatment of PD with constipation. However, it is not clear which ingredients and what mechanism are responsible for the therapeutic effect. In this study, the pharmacodynamic study of WSYGD in PD mice was applied. Concurrently, a novel method for the identification of metabolic profiles of WSYGD has been developed. Finally, we found that WSYGD could protect the PD mice induced by rotenone. The underlying mechanism of the protective effect may be related to the reduction of the DA neurons apoptosis via reducing inflammatory reaction. By virtue of UPLC-MS and chemoinformatics method, 35 prototype compounds and 27 metabolites were filtered out and tentatively characterized. In conclusion, this study provides an insight into the metabolism of WSYGD in vivo to enable understanding of the metabolic process and therapeutic mechanism of PD.

\section{INTRODUCTION}

Parkinson's disease (PD) is the second ranked primary neurodegenerative disease of central nervous system with dysfunction in cortices which affects $2-3 \%$ of the aging population $[1,2]$. Patients typically manifest with motor manifestations, such as movement retardation, stiffness, rest tremor, and postural instability, and nonmotor features [3]. Although, the gold standard tablet treatment for motor symptoms of PD is still levodopa while other types of drugs such as MAO-B inhibitors or beta-blockers have also been utilized [4]. However, 
none of the therapeutic agents in previously could slow down the loss of neuronal cells so as to decelerate or halt the progression of PD [4, 5]. Levodopa-resistant symptoms even conduce to disability and significantly increase the risk of all-cause mortality [6]. Thereby, it is crucial and urgent to search appropriate therapeutic agents with better treatments for PD with western medicine.

Wen-Shen-Yang-Gan decoction (WSYGD) is a TCM utilized for PD by the Nanjing Hospital of Traditional Chinese Medicine, it is formulated by Professor Yang Zhao according to the pathogenesis of endogenous liver wind agitation. It is effective to treat PD with constipation $[7,8]$ and composed of six Chinese herbs: Cistanches Herba (Roucongrong in China, RCR), Paeoniae Radix Alba (Biaoshao in China, BS), Linderae Radix (Wuyao in China, WY), Alpiniae Oxyphyllae Fructus (Yizhi in China, YZ), Dioscoreae Rhizoma (Shanyao in China, SY), Uncariae Ramulus Cum Uncis (Gouteng in China, GT). Our preliminary study showed that the Wen-Shen-Yang-Gan decoction has protective effects on the PD patients and rotenone subacute model mice $[9,10]$. However, compared with studies of its clinical application, the fundamental research of WSYGD alleviates PD have been inadequate.

The metabolism study of TCM will be of vital importance in the discovery and development process of new drugs [11]. Therefore, the research of metabolites and metabolomics-guided drug metabolism allow researchers to investigate the biomarker-clinical relevance [12]. In this respect, the identification of disease biomarkers in metabolomics provides distinctive views on the causes of disease [13, 14]. High performance liquid chromatography coupled with tandem mass spectrometry (LC-MS/MS) have been widely utilized due to, high selectivity, increased sensitivity and high chromatographic resolution, in complex biological matrices [15]. Multivariate statistics, such as principal component analysis (PCA) and orthogonal partial least squares discriminant analysis (OPLS-DA), could be solve the problem that small differences between highly similar species might not be tested but can largely impact the health of outpatients. In the present study, (1) behavioral tests (pole test and rotarod test), were utilized to evaluate the motor and behavioral performance of PD mice in the different groups; (2) the tyrosine hydroxylase (TH) immunofluorescence staining was employed to detect the protection of WSYGD on the damage in striatal neurons; (3) ELISA was utilized to detect the inflammatory cytokines in mice's serum; (4) UPLC-QTOF MS/MS combined with chemoinformatics (PCA and OPLS-DA) for the characterization of metabolic profiles in mouse plasma after oral administration of WSYGD is developed and fully validated to screen out the ingredients absorbed into blood.

\section{MATERIALS AND METHODS}

\section{Chemicals and reagents}

Acetonitrile and methanol (HPLC grade, >=99.9\%) were supplied by Merck ltd. Formic acid was obtained from Sigma-Aldrich. Ultra pure water was purified using the Milli-Q system (Bedford, USA). The reference compounds of rhynchophylline (lot number: wkq18051803), verbascoside (lot number: 120524), linderane (lot number: wkq18031303), geniposidic acid (lot number: wkq18040312), coclaurine (lot number: wkq18036198) were supplied by Sichuan WeikeqiBiotech Co., Ltd., nootkatone were obtained from Chengdu Chroma- Biotechnology Co., Ltd., rutin (lot number: 100080-201811), echinacoside (lot number: 111670-201907), quercetin (lot number:081-9003), and paeoniflorin (lot number:110736-201943) were obtained from National Institutes for Food and Drug Control.

\section{Plant materials}

Cistanches Herba, Alpiniae Oxyphyllae Fructus, Dioscoreae Rhizoma, Paeoniae Radix Alba, Linderae Radix and Uncariae Ramulus Cum Uncis were obtained from Zhengzhou Ruilong pharmaceutical CO., Ltd. and authenticated by Professor Shihui Qian (Jiansu Province Academy of Traditional Chinese Medicine, Nanjing, China).

\section{Water extract of WSYGD preparation}

The weighed powders of RCR (30g), BS (30g), WY (20g), YZ (30g), SY (20g), GT (20g) were mixed and immersed in $1500 \mathrm{~mL}$ of deionized water for $30 \mathrm{~min}$ then decocted using boiling for $1 \mathrm{~h}$. The procedure was repeated twice. The extract was decanted and evaporated under reduced pressure. The mixed decoction was concentrated to high dosage $(4 \mathrm{~g} / \mathrm{mL})$, medium dosage $(2 \mathrm{~g} / \mathrm{mL})$, low dosage $(1 \mathrm{~g} / \mathrm{mL})$. The total ion chromatogram of WSYGD extract of medium dosage were shown in Supplementary Figure 1.

\section{Animal treatment and sample preparation}

\section{Animals and treatments}

Male C57BL/6J mice (ten months old, weighing 30-35g) were provided by Shanghai SLAC Laboratory Animal Co., Ltd (License No. SCXK (Hu), 2007-0005). Animals were housed in a controlled condition $\left(22 \pm 2^{\circ} \mathrm{C}, 55 \pm 5 \%\right.$ humidity $)$ with a $12 \mathrm{~h}$ circadian 
rhythm and had free access to food and water for two weeks to acclimatize them to the environment. Then, they were divided into control group, model group, Wen-Shen-Yang-Gan decoction groups (WSYGD-H, WSYGD-M and WSYGD-L) and drug group (Sinemet, carbidopa/levodopa, $25 / 100 \mathrm{mg}$. $50 \mathrm{mg} / \mathrm{kg}$ ) randomly, 10 mice in each group. The mice in the constituent research divided into control group and model group, 6 mice in each group. All protocols and care for the mice were performed in accordance with the Guidelines for the Care and Use of Laboratory Animals and approved by the Animal Ethics Committee of Nanjing University of Chinese Medicine.

\section{Efficacy of WSYGD to Parkinson's disease}

All of the mice except for control group were intragastrically administered with rotenone $(30 \mathrm{mg} / \mathrm{kg}$, lot number: R8875, sigma, USA). For the control group, an equal volume of normal saline was treated once daily for four weeks. In the 5th to 8th week, the administrated groups mice were received WSYGD solution once a day with different dose $(4 \mathrm{~g} / \mathrm{mL}, 2 \mathrm{~g} / \mathrm{mL}$, $1 \mathrm{~g} / \mathrm{mL}$ ) and the positive group were received Sinemet solution $(0.1 \mathrm{ml} / 10 \mathrm{~g}$, MSD pharmaceutical Co. Ltd.). The mice of other two groups were given an equal volume of normal saline. The Behavioral of mice were evaluated by pole test and rotarod test at $24 \mathrm{~h}$ after experiment. All the animals were sacrificed $24 \mathrm{~h}$ after the behavior test. The concrete drug regimen shown in Figure 1.

\section{Constituents analysis of WSYGD}

The male mice of C57BL/6J were divided into Control group and control-WSYGD group. The control group intragastrically administrated with normal saline each day. The mice of control-WSYGD group received WSYGD extract (dissolved in normal saline) at 14.70 $\mathrm{g} / \mathrm{kg}$. All animals were anesthetized with $10 \%$ urethane. The blood was obtained from the fosse orbital vein of animals at $0.25,0.5,1,2,3,4,6,8 \mathrm{~h}$ after WSYGD treatment.

The blood samples (with heparin and without anticoagulant) were centrifuged (12000 rpm, $10 \mathrm{~min}$, $4^{\circ} \mathrm{C}$ ) to acquire plasma. The sample of various points from one animal were mixed and stored at $-80^{\circ} \mathrm{C}$ until analysis.

\section{Pole test}

The pole test was performed on all mice to assess movement retardation and coordination. A steel pipe (50 $\mathrm{cm}$ long and $1 \mathrm{~cm}$ in diameter) which is tightly wrapped by white antiskid belt and has a spherical protrusion $(2 \mathrm{~cm}$ in diameter) on the top as attachment points of mice. Place the mouse's head upward on the spherical protrusion, record the time from its placement on the pole top to the point of turning its head downwards and the total time from its placement on the pole top to its climbing to the pole bottom with its rear limbs touching the ground. Three trials were performed with each mouse with an interval of two minutes and median data were taken across the trials.

\section{Rotarod test}

The rotarod test was performed with the help of ZH-600 mouse rotarod fatigue meter (Anhui Zhenghua biologic apparatus facilities Co., Ltd). The mice were placed on a rotation drum and measurement the time of standing on the drum as the speed accelerated from five to forty rpm in five-minute. Place the mice on a shifting drum, increase the rotation speed from $5 \mathrm{rpm}$ to $40 \mathrm{rpm}$ in 5 minutes, and record the time of standing on the drum. Final trials were performed three times for each animal in every group, and the values were averaged for every animal. The experimental environment, light and temperature for example, and timing were compatible in all the tests.

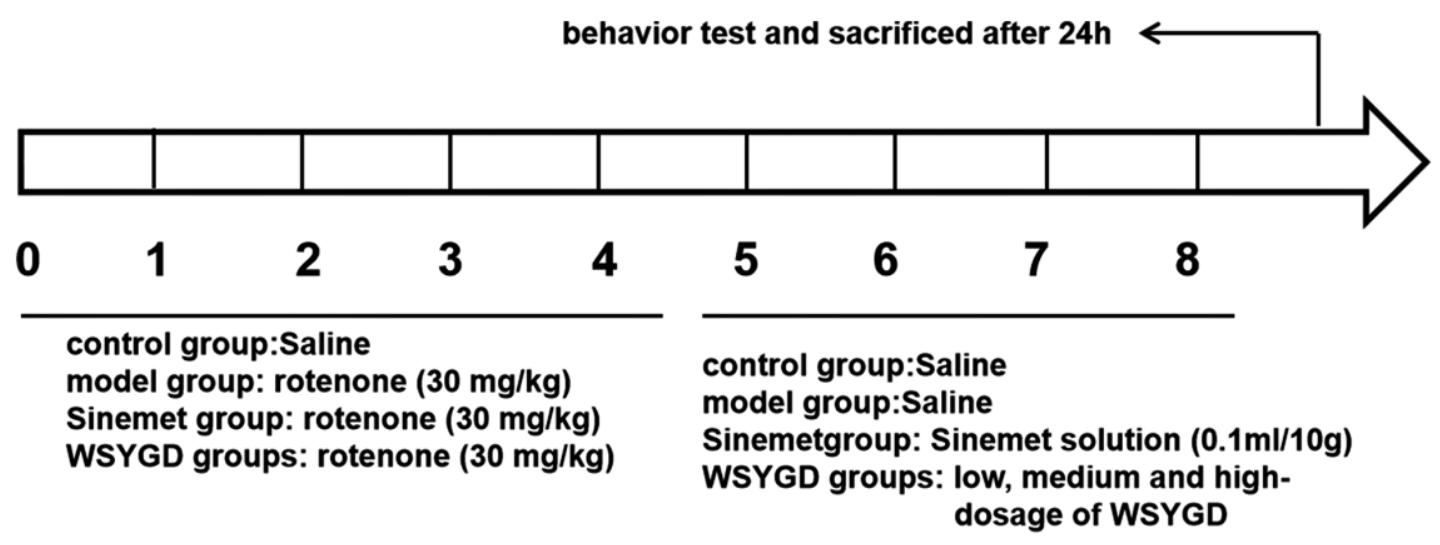

Figure 1. Schematic representation of experiment. 


\section{Immunofluorescence staining}

After perfusion, the tissue samples of mice were rapidly removed and fixed with $4 \%$ paraformaldehyde overnight. Sucrose solution was utilized to store isolated brains to dehydrate gradiently and embedded in OCT for frozen tissue sections. The substantia nigra brain tissue sections in line with the brain atlas were prepared. Goat anti-mouse IgG (H\&L, ab150113, Abcam, Cambridge, UK) was appended and hatched for one hour after being flushed with PBS. The sample was washed by PBS and sealed with anti- fluorescence. The flake was observed by Olympus BX63 fluorescent microscope (Olympus Corporation, Tokyo, Japan).

\section{Western blotting (WB) analysis}

Mid-brains of mice were rinsed with PBS and lysed with radioimmunoprecipitation assay buffer and then centrifuged $\left(12000 \mathrm{rpm}, 10\right.$ minutes, $\left.4^{\circ} \mathrm{C}\right)$ Then, Lysates were segregated by $12 \%$ SDS-PAGE and transferred to polyvinylidene fluoride membrane (Millipore, Danvers, MA, USA), blocked in 5\% BSA in PBS and pre-incubated with primary antibodies as the a-syn (ab59264, Abcam, Cambridge, UK), TH (SAB4200697, Sigma-Aldrich, USA) and GAPDH (60004-1-Ig, ProteinTech Group, Inc., USA). The GAPDH antibody was utilized as a loading control. On the second day, the PVDF membrane was incubated after flushed by TBST solution for one hour at $4^{\circ} \mathrm{C}$. The membranes were exposed to anti-rabbit IgG antibodies (HRP, ZB-2301, Beijing Zhongshan Jinqiao Biotechnology Co., Ltd., China) for one hour at $4^{\circ} \mathrm{C}$ and scanned with a chemiluminescence image analysis system (Tanon-5200, Tanon Science and Technology Co., Ltd, China).

\section{Quantization of cytokine levels by enzyme-linked immunosorbent assay (ELISA)}

The blood was collected and clarified, then centrifugated at $12000 \mathrm{rpm}$ for $10 \mathrm{~min}$ at $4^{\circ} \mathrm{C}$, and the supernatant was utilized for analysis. The levels of supernatant cytokines (all of obtained from Shanghai ZCi Biotechnology Co., Ltd., China), such as IL-10, TNF- $\alpha$, and IL- $1 \beta$, were determined by ELISA kits. Standards and samples were incubated by diluent in a plate coated with primary antibody for one hour at room temperature. Plates were then washed three times and $100 \mu \mathrm{L}$ of substrate solution (tetramethylbenzidine) was added to each well for chromogenic reaction for 15 minutes in complete darkness. Diluted standards and samples were appended to each well and incubation with biotin-labelled secondary antibodies. Then, the plate was incubated by horseradish peroxidaseconjugated streptavidin (SA-HRP). The reaction halted by adding $50 \mu \mathrm{L}$ of stop solution into each well. The standard curve was constructed using the absorbance of each standard (450nm, vertical axis) against its concentration (horizontal axis). The concentration of inflammatory cytokines was calculated using the relative absorbance of the samples and standards.

\section{Reference and plant sample preparation}

A standard mixture containing rhynchophylline, verbascoside, linderane, geniposidic acid, coclaurine, nootkatone, rutin, echinacoside, quercetin and paeoniflorin was prepared in $100 \%$ methanol.

An aliquot of 10 milliliter of the WSYGD solution was decanted and evaporated under reduced pressure. The residue was dissolved in 10 milliliter of methanol and vortex-mixed for $5 \mathrm{~min}$. The sample was centrifugated with $12000 \mathrm{rpm}$ for $10 \mathrm{~min}$ at room temperature and then filtered through a $0.22 \mathrm{~mm}$ membrane.

\section{Instrument and analytical conditions}

Metabolite analysis was achieved using a Waters ACQUITY UPLCTM I-Class chromatography system (Waters Corp, Milford, MA, USA) equipped with ion mobility mass spectrometry detector. The separation was performed on a Thermo Scientific ${ }^{\mathrm{TM}}$ Syncronis $^{\mathrm{TM}}$ C18 (100 mm×2.1 mm, 1.7 mum particle size, Thermo Fisher Scientific) and the injection volume was $5 \mu \mathrm{L}$ at $25^{\circ} \mathrm{C}$. A gradient elution profile was employed using mobile phase A ( $0.1 \%$ formic acid in acetonitrile) and mobile phase B $(0.1 \%$ formic acid in water $)$. The following gradient was utilized: $0 \mathrm{~min}, 5 \% \mathrm{~A} ; 0.5 \mathrm{~min}$, $5 \% \mathrm{~A} ; 3 \mathrm{~min}, 40 \% \mathrm{~A} ; 10.5 \mathrm{~min}, 95 \% \mathrm{~A}$. The flow rate was set to $0.40 \mathrm{~mL} / \mathrm{min}$.

The mass spectrometry was carried out using a SYNAPT G2-Si Q TOF (Waters Corp, Wilmslow, UK) connected to the ACQUITY UPLC I-Class System via an ESI interface. The mass spectrometry analysis was performed in the positive mode and negative mode, with the following parameters: Capillary $1.5 \mathrm{kV}$, sample voltage $30 \mathrm{~V}$, cone voltages $5 \mathrm{~V}$, source temperature $120^{\circ} \mathrm{C}$, desolvation temperature $500^{\circ} \mathrm{C}$. desolvation gas flow rate $800 \mathrm{~L} / \mathrm{h}$, cone gas flow rate $50 \mathrm{~L} / \mathrm{h}$. The MS was set with 0.1 second of scan time to acquire in sensitivity mode. The accurate mass precursor and fragment ion data was obtained using the selected mass range of $\mathrm{m} / \mathrm{z} 100-1200$.

\section{Data processing}

\section{The mechanism of WSYGD in PD}

All data were expressed as mean \pm SD and statistical significance by using one-way ANOVA followed by 
post-hoc analysis using the GraphPad Prism software, (version 8.0, San Diego, CA, USA). Ultimately, the data that $\mathrm{P}<0.05$ was deemed to be significant.

\section{Composition identification}

The resultant data matrices from the analytical technique were introduced into the Masslynx ${ }^{\mathrm{TM}}$ NT 4.1 software (Waters Corporation) for multi-variate statistical analysis including PCA and OPLS-DA. Pareto scaling was performed through Principal component analysis to catch sight of the separation between groups, and OPLS-DA to recognition important characteristics using Masslynx v.4.1 (Waters, Milford, MA, USA) [16]. We utilize the database of HMDB, Massbank and KEGG to screen and discriminate the potential markers.

\section{RESULTS AND DISCUSSION}

\section{Effects of WSYGD on behavioral test of rotenone- intoxicated mice}

In the behavioral test of pole, the turning around time of mice head in the rotenone-intoxicated group was obviously longer than control group mice, while the turning around time of mice head in the WSYGD-H, WSYGD-M and WSYGD-L groups were significantly shortened, indicating statistically significant in comparison with model. With regard to the total time of climbing, the mice in rotenone-intoxicated group obviously longer than those in control group, and the time spent by WSYGD-H and WSYGD-M was significantly shortened, indicating statistically significant in comparison with model. In behavioral test of rotarod, the time of rod-standing time of rotenone-intoxicated group mice were obviously shorter than that of control, moreover, the WSYGD$\mathrm{H}$, WSYGD-M and WSYGD-L group mice were obviously longer than rotenone-intoxicated group, the results shown in Figure 2.
Effects of WSYGD on midbrain dopamine (DA) neurons and pathological changes of $\alpha$-syn in rotenone-intoxicated mice

The TH-positive cells number could be utilized to reflect the dopamine neurons numbers. The WB results shown that the $\mathrm{TH}$ expression in rotenone-intoxicated group was evidently down-regulated than that in the control group, and that in WSYGD-H, WSYGD-M and WSYGD-L groups were significantly increased in comparison with that in model group (Figure 3B). The same results were also indicated among the immunofluorescence test (Figure 3A). Simultaneously, the $\alpha$ syn expression among the middle brain of mice in the rotenone-intoxicated group was evidently upwardregulated than that in the control group, and WSYGD$\mathrm{H}$, WSYGD-M and WSYGD-L could obviously decrease the expression of $\alpha$-syn (Figure 3B).

Effects of WSYGD on peripheral immunity of rotenone-intoxicated mice

The result of ELISA shown that the inflammatory cytokines contents such as TNF- $\alpha$, IFN- $\gamma$, IL-1 $\beta$, IL-22, and IL-17 in the mice serum of rotenone-intoxicated group were obviously increased than those in normal group. However, IGF- 1 and TGF- $\beta 1$ in rotenoneintoxicated group were evidently lower than that in the normal group. Simultaneously, WSYGD could reverse such phenomenon (Figure 4).

\section{UPLC-MS characterization of chemical components from WSYGD}

All mass spectrum data acquired in the LC-MS/MS analysis were utilized to recognize the metabolites structures which was essential for structural confirmation of the biomarkers by the procedures as described in the before-mentioned. The UPLCQTOF/MS analysis platform provided the precise

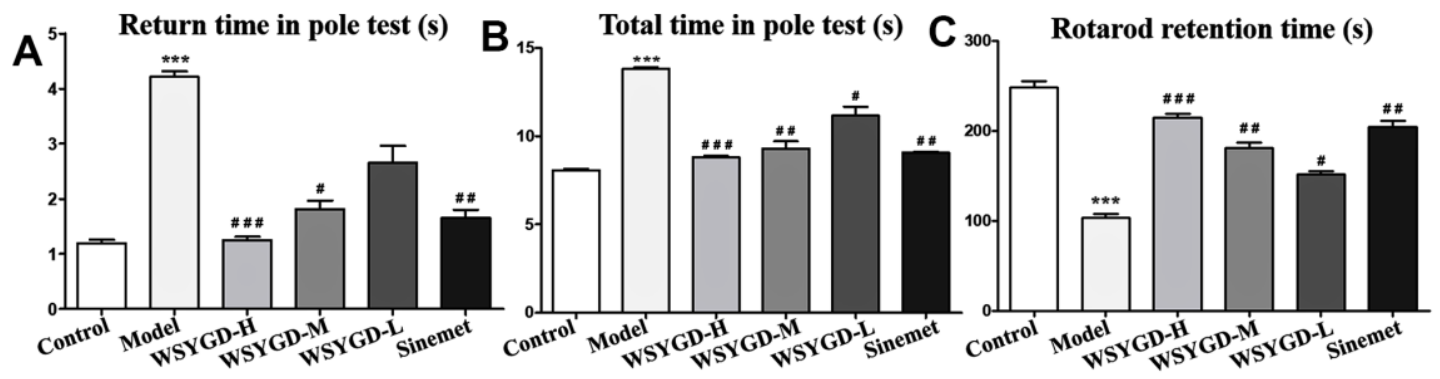

Figure 2. Effects of WSYGD on behavioral test of PD chronic model mice. In the pole test, (A) refers to the turning time and (B) refers to the total time; (C) refers to the retention time in the rotarod test. Control: blank group; Model: rotenone-intoxicated group; WSYGD$\mathrm{H}$ : high dosage group; WSYGD-M: medium dosage group; WSYGD-L: Low dosage group; Sinemet: positive control. ${ }^{* * *}$ p<0.001 vs. Control; $\# p<0.05$,\#\# <0.01, \#\#\#p<0.001 vs. Model. 
molecular mass within measurement errors $(<5 \mathrm{ppm})$, allowing the potential element composition, unsaturation degree and fractional isotope abundance of the compounds to be determined. Total ion chromategrams were obtained by LC-MS/MS (Supplementary Figure 1). A total of 97 peaks were obtained and confirmed or tentatively preliminarily peculiarity (Figure 5 and Supplementary Table 1). For instance, the molecular weight of 37 peak is 623.1969 , and the main fragment ions analyzed by MS/MS screening were surveyed at $\mathrm{m} / \mathrm{z} 605.1870\left[\mathrm{M}-\mathrm{H}_{3} \mathrm{O}\right]-, 487.1452[\mathrm{M}-$
$\left.\mathrm{C}_{8} \mathrm{H}_{9} \mathrm{O}_{2}\right]-, 477.1397 \quad\left[\mathrm{M}-\mathrm{C}_{6} \mathrm{H}_{11} \mathrm{O}_{4}\right]-, \quad 179.0344 \quad[\mathrm{M}-$ $\left.\mathrm{C}_{20} \mathrm{H}_{29} \mathrm{O}_{11}\right]-, 161.0239$ [M- $\left.\mathrm{C}_{23} \mathrm{H}_{25} \mathrm{O}_{10}\right]$-. Therefore, the elemental composition of ion 37 was calculated to be $\mathrm{C}_{29} \mathrm{H}_{36} \mathrm{O}_{15}$ and identified as acteoside.

Multivariate statistical analysis for in vivo discrimination of WSYGD

The raw data were collected by the SYNAPT G2-Si QTOF before analysis. The representative total ion chromatograms (TICs) of WSYGD in mice were shown

A

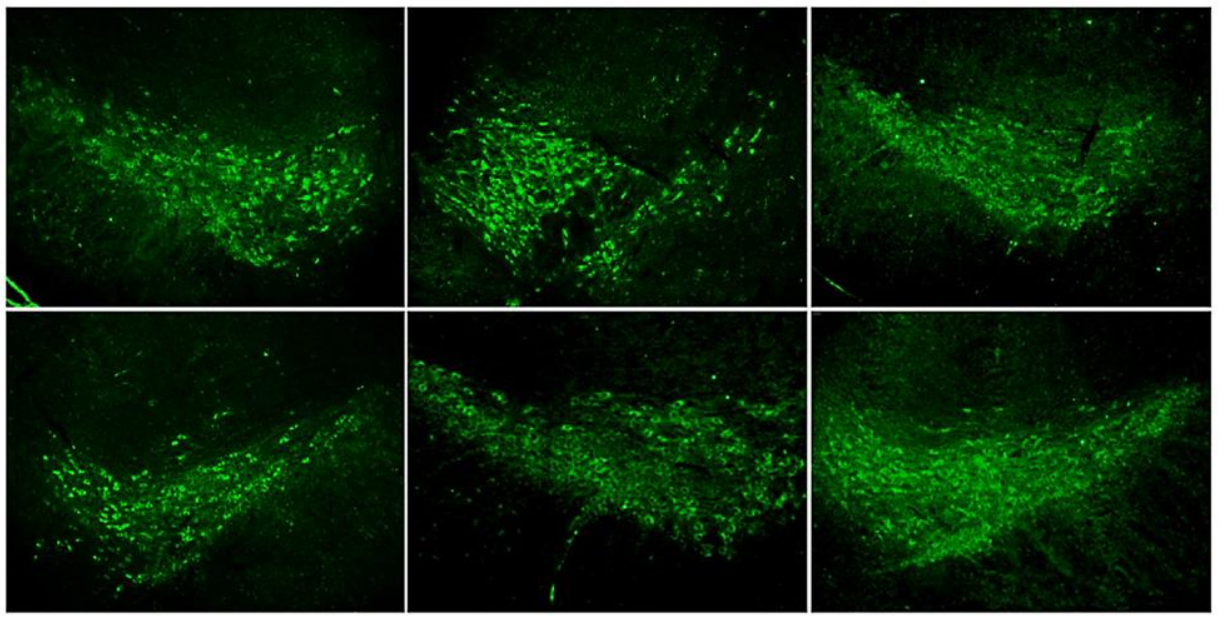

B
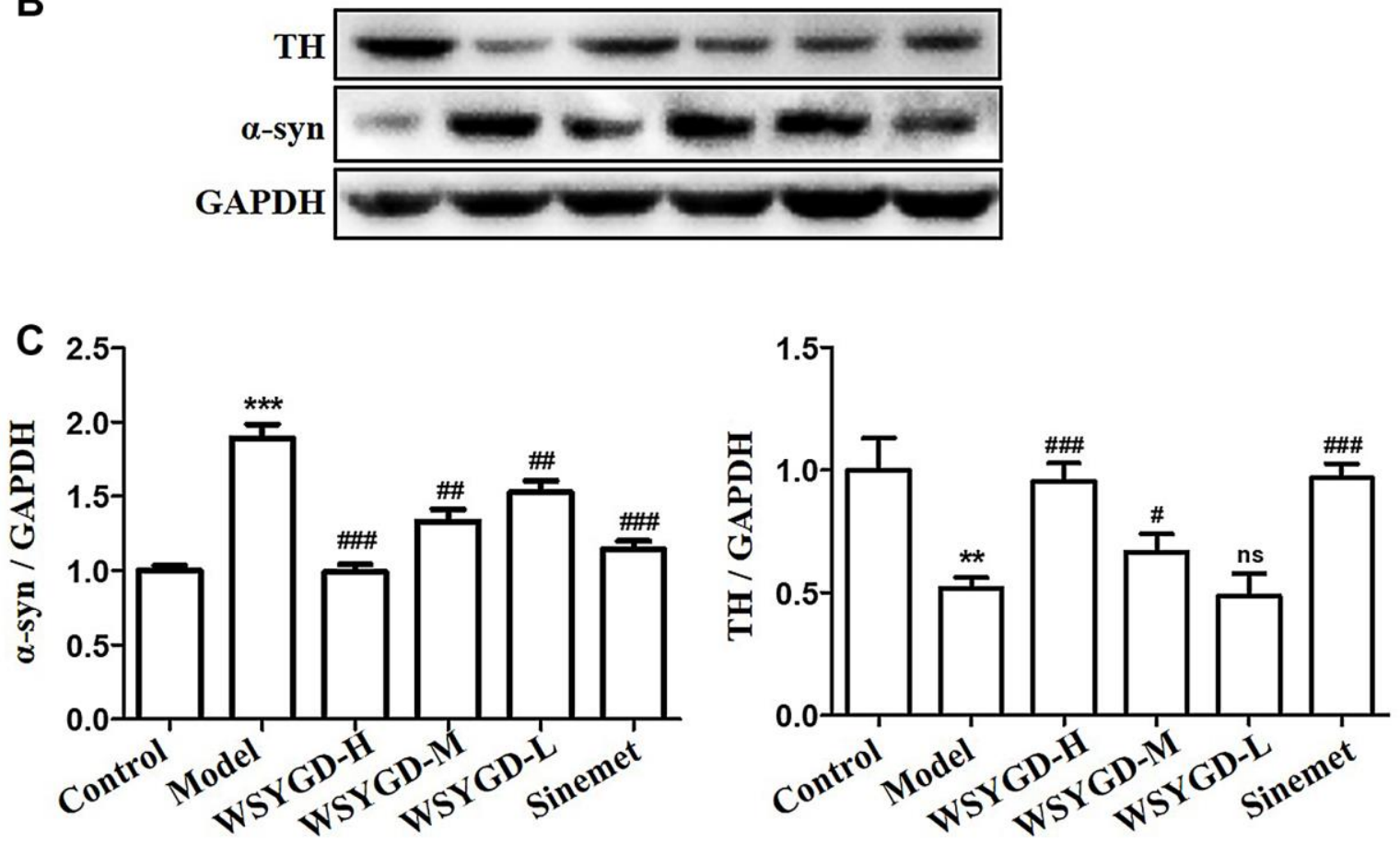

Figure 3. Immunofluorescence staining of TH protein in the substantia nigra of mice (A); Western blotting analysis (B) and quantification (C) of relative $\alpha$-syn and TH protein abundance. Control: blank group; Model: rotenone-intoxicated group; WSYGD-H: high dosage group; WSYGD-M: medium dosage group; WSYGD-L: Low dosage group; Sinemet: positive control. ${ }^{* *} p<0.01,{ }^{* * *} p<0.001$ vs control; \#p<0.01, $\# \#$ < 0.01 , \#\#\#p<0.001 vs Model. 

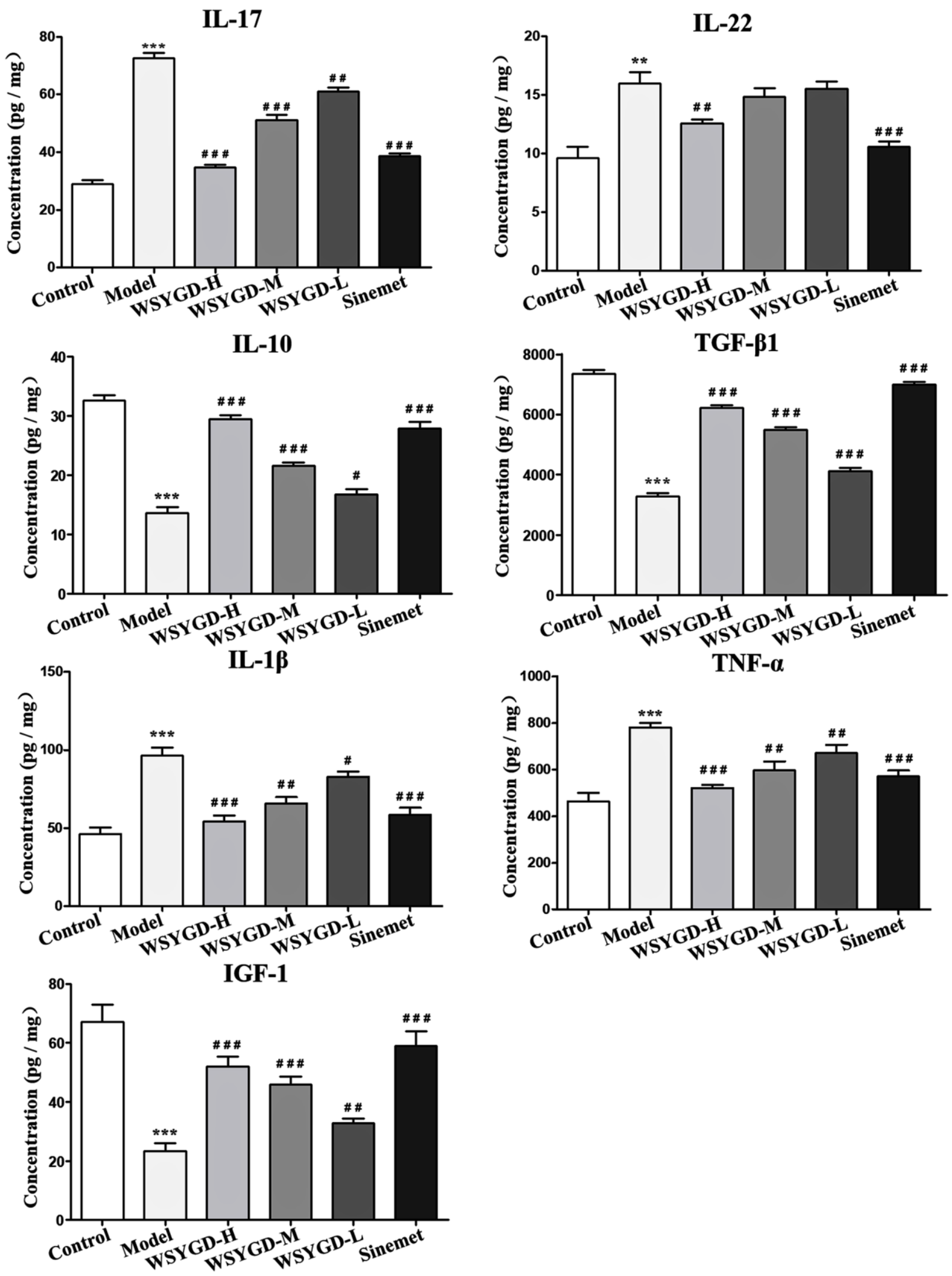

Figure 4. Changes of serum inflammatory factors including IL-10, IL-17, IL-22, IL-10, TGF- $\beta 1$, TNF- $\alpha$, IGF-1, IL-1 $\beta$ and NF- $\kappa B$ in Mice. Control: blank group; Model: rotenone-intoxicated group; WSYGD-H: high dosage group; WSYGD-M: medium dosage group; WSYGD-L:

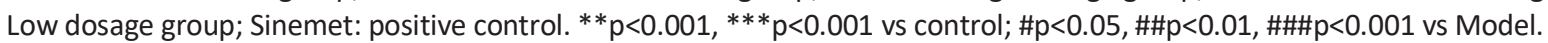




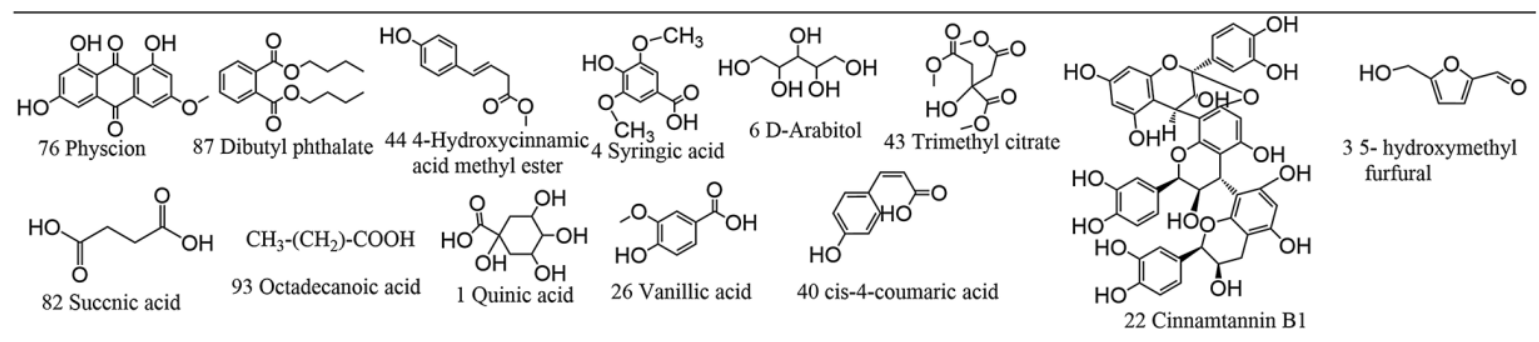

Figure 5. Chemical structures of WSYGD identified using UPLC-ESI-Q-TOF MS. 
in Supplementary Figure 2. To compare the difference between control group and WSYGD group, unsupervised PCA and supervised OPLS-DA were produced and the results data were displayed as PCA scores plot (Figure 6A, 6B). The samples from WSYGD and normal group clusters were obviously diverse indicating that the clear discrimination between two groups.

To find the potential quality markers, OPLS-DA analysis was performed to emerge S-plot (Figure 6C, 6D). As it could be observed in Figure 6C, 6D every point symbolizes an ion $t_{R}-m / z$ pair; the $X$-axis symbolizes the ingredient contribution and the $\mathrm{Y}$-axis symbolizes the ingredient confidence. The farther away the distance is from the origin the greater the contribution to classification. Thus, the variables located at the two ends of "S" sharp were the compounds which are more important to discriminating the two groups, namely potential characteristic chemical markers. Then, to minimize complex data, further filtering procedures based on VIP value (VIP $>1$ ) analysis were performed (Figure 6E, 6F). It turns out that 62 variables were screened out, including 23 and 39 ions in positive mode and negative mode, respectively. Simultaneously, the result of the variables being summarized in ESI, Table 1.
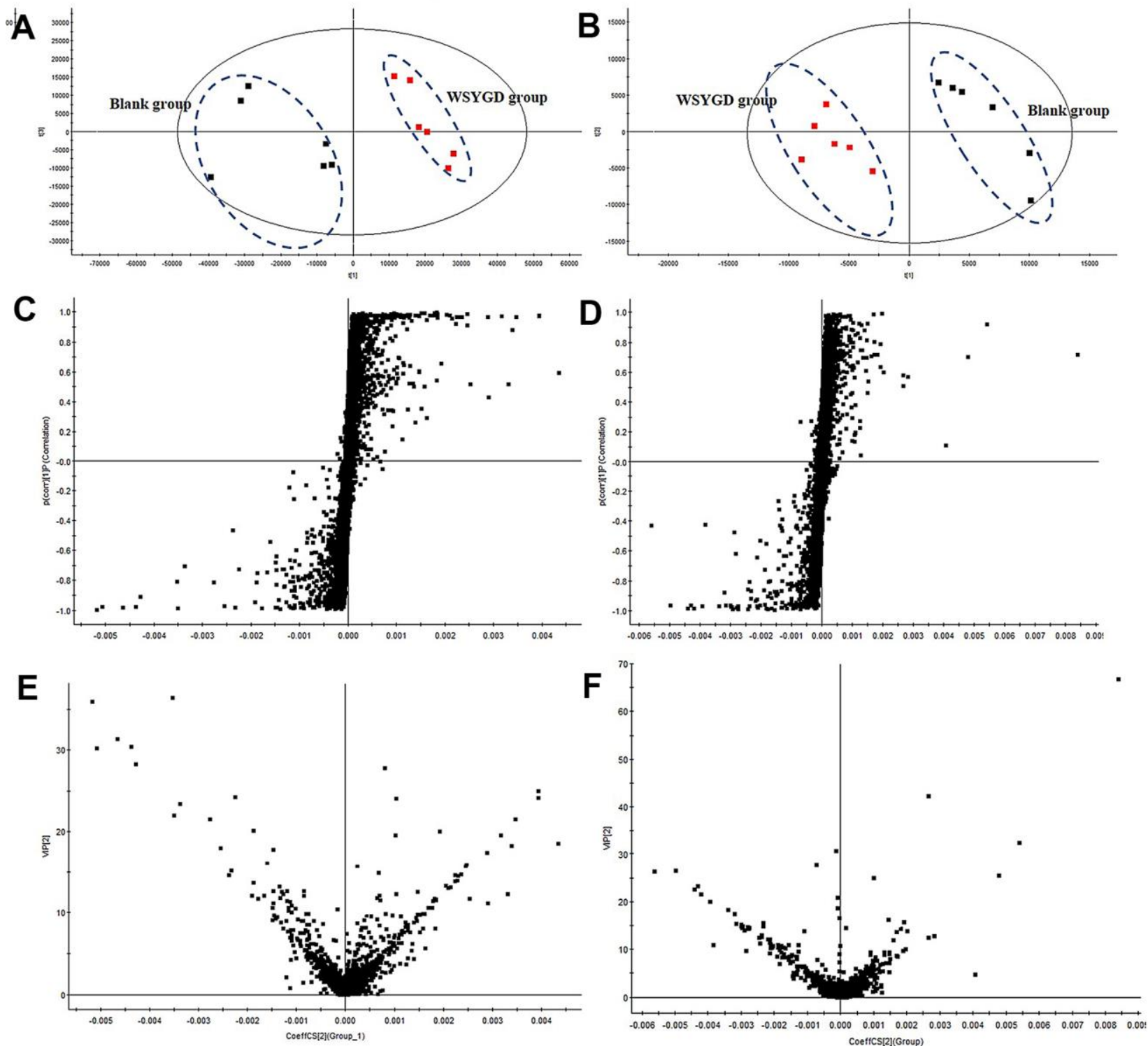

Figure 6. PCA score plot of all analyzed samples in positive-ion (A) mode and negative-ion (B) mode with the statistical parameters; S-plot of OPLS-DA in positive-ion (C) mode and negative-ion (D) mode with the statistical parameters; VIP value plot in positive-ion (E) mode and negative-ion $(\mathbf{F})$ mode. 
Table 1. Identification of prototype compounds and metabolites of WSYGD in mouse plasma by UPLC-ESI-QTOF MS.

\begin{tabular}{|c|c|c|c|c|c|c|c|c|}
\hline No. & $t_{R}(\min )$ & $\begin{array}{l}\text { Detected } \\
\text { mass }[\mathrm{M}-\mathrm{H}]^{-} \\
/[\mathrm{M}+\mathrm{H}]^{+}\end{array}$ & $\begin{array}{l}\text { Theoretical } \\
\text { exact mass } \\
\text { (Da) }\end{array}$ & $\begin{array}{l}\text { Mass } \\
\text { error } \\
(\mathbf{p p m})\end{array}$ & $\begin{array}{l}\text { Molecular } \\
\text { formula }\end{array}$ & MS/MS (m/z) & Assigned identity & Source \\
\hline M1 & 0.402 & 201.1120 & 201.1127 & -3.5 & $\mathrm{C}_{10} \mathrm{H}_{16} \mathrm{O}_{4}$ & $201.1120,157.1128$ & Paeonimetabolin II & PL \\
\hline M2 & 0.720 & 297.0616 & 297.0610 & 2.0 & $\mathrm{C}_{13} \mathrm{H}_{14} \mathrm{O}_{8}$ & $121.0132,103.0170$ & Benzoic acid-O-glucuronide & PL \\
\hline P1 & 0.771 & 285.0760 & 285.0763 & -1.1 & $\mathrm{C}_{16} \mathrm{H}_{12} \mathrm{O}_{5}$ & $285.0760,307.0574,323.0312$ & Maackiain & UR \\
\hline M3 & 0.802 & 232.9749 & 232.9756 & -3.0 & $\mathrm{C}_{7} \mathrm{H}_{6} \mathrm{O}_{7} \mathrm{~S}$ & 153.0181 & Protocatechuate-3-O-sulfate & PL \\
\hline P2 & 0.803 & 118.0871 & 118.0868 & 2.5 & $\mathrm{C}_{5} \mathrm{H}_{11} \mathrm{NO}_{2}$ & $118.0871,74.0972$ & Glycine betaine & $\mathrm{CH}$ \\
\hline P3 & 0.950 & 119.0344 & 119.0344 & 0 & $\mathrm{C}_{4} \mathrm{H}_{6} \mathrm{O}_{4}$ & $119.0344,141.0171,136.0615$ & Succnic acid & $\mathrm{AO}$ \\
\hline P4 & 1.330 & 181.0493 & 181.0501 & -4.4 & $\mathrm{C}_{9} \mathrm{H}_{8} \mathrm{O}_{4}$ & $\begin{array}{l}\text { 163.0391, 151.0385, 135.0441, } \\
105.0341,71.0133\end{array}$ & Caffeic acid & UR \\
\hline P5 & 1.604 & 375.1320 & 375.1291 & 4.5 & $\mathrm{C}_{16} \mathrm{H}_{22} \mathrm{O}_{10}$ & $\begin{array}{l}375.1284,313.1287,213.0727, \\
179.0708,121.0653\end{array}$ & Geniposidic acid & $\mathrm{CH}$ \\
\hline M4 & 1.614 & 279.0172 & 279.0175 & -1.1 & $\mathrm{C}_{9} \mathrm{H}_{10} \mathrm{O}_{8} \mathrm{~S}$ & $279.0172,199.0604,300.9994$ & 3,4-di-methoxygallate sulfate & PL \\
\hline P6 & 1.625 & 311.1649 & 311.1647 & 0.6 & $\mathrm{C}_{20} \mathrm{H}_{22} \mathrm{O}_{3}$ & 311.1649 & Yakuchinone B & $\mathrm{AO}$ \\
\hline P7 & 2.020 & 371.1334 & 371.1342 & -2.2 & $\mathrm{C}_{17} \mathrm{H}_{22} \mathrm{O}_{9}$ & $371.1334,185.0809$ & Sinapaldhyde glucoside & $\mathrm{CH}$ \\
\hline P8 & 2.100 & 355.1015 & 355.1029 & -3.9 & $\mathrm{C}_{16} \mathrm{H}_{18} \mathrm{O}_{9}$ & $355.1015,127.1123$ & Chlorogenic acid & UR \\
\hline P9 & 2.239 & 415.1018 & 415.1029 & -2.6 & $\mathrm{C}_{21} \mathrm{H}_{20} \mathrm{O}_{9}$ & $415.1018,399.1080$ & Daidzin & DO \\
\hline P10 & 2.278 & 369.1172 & 369.1186 & -3.8 & $\mathrm{C}_{17} \mathrm{H}_{20} \mathrm{O}_{9}$ & $369.1172,333.0968,259.0818$ & Methyl chlorogenate & UR \\
\hline P11 & 2.281 & 577.1325 & 577.1346 & -3.6 & $\mathrm{C}_{30} \mathrm{H}_{26} \mathrm{O}_{12}$ & $577.1325,287.0614,559.1246$ & Proanthocyanidins & LR \\
\hline P12 & 2.290 & 343.1408 & 343.1393 & 4.4 & $\mathrm{C}_{16} \mathrm{H}_{22} \mathrm{O}_{8}$ & $\begin{array}{l}343.1408,165.0922,325.1274 \\
314.1393,298.1083,\end{array}$ & Coniferin & $\mathrm{CH}$ \\
\hline P13 & 2.340 & 314.1393 & 314.1392 & -1 & $\mathrm{C}_{18} \mathrm{H}_{21} \mathrm{NO}_{4}$ & $\begin{array}{l}296.1290,286.1445,282.1133, \\
270.1135,256.1348,192.1022\end{array}$ & Coclaurine & LR \\
\hline P14 & 2.479 & 329.0654 & 329.0661 & -2.1 & $\mathrm{C}_{17} \mathrm{H}_{14} \mathrm{O}_{7}$ & $329.0654,375.0728$ & Tricin & UR \\
\hline P15 & 2.560 & 785.2506 & 785.2504 & 0.3 & $\mathrm{C}_{35} \mathrm{H}_{46} \mathrm{O}_{20}$ & $\begin{array}{l}623.2489,461.2521,315.2489, \\
161.2402\end{array}$ & Echinacoside & $\mathrm{CH}$ \\
\hline P16 & 2.610 & 235.0810 & 235.0818 & -3.4 & $\mathrm{C}_{9} \mathrm{H}_{14} \mathrm{O}_{7}$ & $235.0810,176.0670,114.0317$ & Trimethyl citrate & DO \\
\hline P17 & 2.637 & 312.1598 & 312.1600 & -0.6 & $\mathrm{C}_{19} \mathrm{H}_{21} \mathrm{NO}_{3}$ & $312.1598,283.1325,350.1147$ & Pronuciferine & LR \\
\hline P18 & 2.680 & 623.1976 & 623.1976 & 0 & $\mathrm{C}_{29} \mathrm{H}_{36} \mathrm{O}_{15}$ & $\begin{array}{l}647.1799,605.1876,477.1402, \\
179.0350,161.0244\end{array}$ & Acteoside & $\mathrm{CH}$ \\
\hline P19 & 2.720 & 609.1447 & 609.1456 & -1.5 & $\mathrm{C}_{27} \mathrm{H}_{30} \mathrm{O}_{16}$ & $\begin{array}{l}465.1019,303.1540,287.1847,300.195 \\
6,271.6077\end{array}$ & Rutin & DO \\
\hline $\mathrm{P} 20$ & 2.860 & 479.1554 & 479.1553 & -0.2 & $\mathrm{C}_{23} \mathrm{H}_{28} \mathrm{O}_{11}$ & $479.1554,525.1622,316.0961$ & Paeoniflorin & PL \\
\hline M5 & 2.980 & 465.1397 & 465.1397 & 0.0 & $\mathrm{C}_{22} \mathrm{H}_{26} \mathrm{O}_{11}$ & $345.0609,327.0577,289.1096$ & $\begin{array}{l}\text { Demethylene hydroxyl } \\
\text { oxypaeoniflorin }\end{array}$ & PL \\
\hline $\mathrm{P} 21$ & 3.592 & 259.0974 & 259.0970 & 1.5 & $\mathrm{C}_{15} \mathrm{H}_{16} \mathrm{O}_{4}$ & $\begin{array}{l}259.0974,241.0866,231.1027, \\
213.0919\end{array}$ & Linderane & LR \\
\hline M6 & 3.930 & 507.1758 & 507.1749 & 1.8 & $\mathrm{C}_{21} \mathrm{H}_{32} \mathrm{O}_{14}$ & $\begin{array}{l}345.1164,327.1046,283.1035, \\
165.1022,121.1049\end{array}$ & $\begin{array}{l}\text { Desbenzoyl product of } \\
\text { paeoniflorin-O-glucuronide }\end{array}$ & PL \\
\hline $\mathrm{P} 22$ & 4.341 & 269.0456 & 269.0450 & 2.2 & $\mathrm{C}_{15} \mathrm{H}_{10} \mathrm{O}_{5}$ & $269.0456,251.0356,315.0505$ & Genistein & UR \\
\hline M7 & 4.520 & 261.0068 & 261.0069 & -0.4 & $\mathrm{C}_{9} \mathrm{H}_{10} \mathrm{O}_{7} \mathrm{~S}$ & $215.0123,171.0015$ & $\begin{array}{l}\text { 3,4-dihydroxyphenylpropionate } \\
\text { sulfate }\end{array}$ & PL \\
\hline M8 & 4.560 & 261.0081 & 261.0069 & 4.6 & $\mathrm{C}_{9} \mathrm{H}_{10} \mathrm{O}_{7} \mathrm{~S}$ & $261.0081,242.9960,224.9858$ & $\begin{array}{l}\text { Dihydroxyphenylpropionate } \\
\text { sulfate }\end{array}$ & LR \\
\hline $\mathrm{P} 23$ & 4.603 & 301.0349 & 301.0348 & 0.3 & $\mathrm{C}_{15} \mathrm{H}_{10} \mathrm{O}_{7}$ & $301.0349,283.0255,107.0135$ & Quercetin & LR \\
\hline P24 & 4.250 & 385.2134 & 385.2127 & 1.8 & $\mathrm{C}_{22} \mathrm{H}_{28} \mathrm{~N}_{2} \mathrm{O}_{4}$ & $407.1909,269.1715,160.0771$ & Rhynchophylline & UR \\
\hline P25 & 4.960 & 429.1172 & 429.1186 & -3.3 & $\mathrm{C}_{22} \mathrm{H}_{22} \mathrm{O}_{9}$ & $429.1172,267.0670$ & Ononin & DO \\
\hline M9 & 5.050 & 199.0970 & 199.0980 & 5 & $\mathrm{C}_{10} \mathrm{H}_{14} \mathrm{O}_{4}$ & $151.1002,123.0988,108.0978$ & Paeonimetabolin I & PL \\
\hline M10 & 5.424 & 389.1057 & 389.1059 & -0.5 & $\mathrm{C}_{20} \mathrm{H}_{22} \mathrm{O}_{6} \mathrm{~S}$ & $389.1057,779.2169$ & Yakuchinone B-O-sulfate & $\mathrm{AO}$ \\
\hline M11 & 5.530 & 449.1440 & 449.1448 & -1.8 & $\mathrm{C}_{17} \mathrm{H}_{24} \mathrm{O}_{10}$ & $\begin{array}{l}327.1077,309.0975,287.0925,165.054 \\
9\end{array}$ & $\begin{array}{l}\text { Demethylene hydroxyl } \\
\text { paeoniflorin }\end{array}$ & PL \\
\hline M12 & 5.620 & 399.1905 & 399.1920 & -3.8 & $\mathrm{C}_{22} \mathrm{H}_{26} \mathrm{~N}_{2} \mathrm{O}_{5}$ & $\begin{array}{l}\text { 797.3782, 421.1731, 399.1905, } \\
226.1454,196.0944,174.0511, \\
146.0638\end{array}$ & $\begin{array}{l}\text { Dehydrogenation and hydroxy } \\
\text { rhynch-ophylline }\end{array}$ & UR \\
\hline M13 & 5.650 & 383.0447 & 383.0437 & 2.6 & $\mathrm{C}_{16} \mathrm{H}_{15} \mathrm{O}_{9} \mathrm{~S}$ & $201.8997,179.9805,106.9908$ & 3-O-methylepicatechin-O-sulfate & PL \\
\hline M14 & 5.720 & 285.0756 & 285.0763 & -2.5 & $\mathrm{C}_{16} \mathrm{H}_{12} \mathrm{O}_{5}$ & $285.0756,267.0666,307.0575$ & Izalpinia & $\mathrm{AO}$ \\
\hline M15 & 5.758 & 375.1291 & 375.1289 & -0.5 & $\mathrm{C}_{16} \mathrm{H}_{24} \mathrm{O}_{10}$ & $375.1291,345.1186$ & Desbenzoylpaeoniflorin & PL \\
\hline M16 & 6.288 & 460.1612 & 460.1608 & 0.9 & $\mathrm{C}_{23} \mathrm{H}_{27} \mathrm{NO}_{9}$ & $460.1612,506.1664,921.3318$ & Coclaurine-O-glucuronide & LR \\
\hline M17 & 6.560 & 399.1911 & 399.1920 & -2.3 & $\mathrm{C}_{22} \mathrm{H}_{28} \mathrm{~N}_{2} \mathrm{O}_{5}$ & $399.1911,445.1967$ & Hydroxyrhynchophylline & UR \\
\hline M18 & 6.694 & 491.2295 & 491.2281 & 2.8 & $\mathrm{C}_{26} \mathrm{H}_{34} \mathrm{O}_{9}$ & $491.2295,473.2177,455.2087$ & Oxyphyllacinol-O-glucuronide & $\mathrm{AO}$ \\
\hline P26 & 7.014 & 285.0406 & 285.0399 & 2.5 & $\mathrm{C}_{15} \mathrm{H}_{10} \mathrm{O}_{6}$ & $285.0406,249.0190,249.0190$ & Kaempferol & UR \\
\hline P27 & 7.392 & 413.3763 & 413.3783 & -4.8 & $\mathrm{C}_{29} \mathrm{H}_{50} \mathrm{O}$ & $413.3763,443.3904,371.3318$ & Sitosterol/isomer & LR \\
\hline P28 & 7.410 & 21 & 218 & -2.3 & $\mathrm{C}_{15} \mathrm{H}_{22} \mathrm{O}$ & $\begin{array}{l}203.9254,190.0854,161.5551,147.943 \\
7\end{array}$ & Nootkatone & $\mathrm{AO}$ \\
\hline M19 & 7.991 & 527.0490 & 527.0496 & -1.1 & $\mathrm{C}_{21} \mathrm{H}_{18} \mathrm{O}_{14} \mathrm{~S}$ & $527.0490,1055.1084$ & Genistein-O-sulfate & UR \\
\hline M20 & 7.849 & 151.0401 & 151.0395 & 4 & $\mathrm{C}_{8} \mathrm{H}_{8} \mathrm{O}_{3}$ & $151.0401,135.0442,303.0870$ & $\begin{array}{l}\text { Pyrolysis production of ferulic } \\
\text { acid }\end{array}$ & UR \\
\hline
\end{tabular}




\begin{tabular}{lllllllll} 
M21 & 8.703 & 493.1714 & 493.1710 & 0.8 & $\mathrm{C}_{24} \mathrm{H}_{30} \mathrm{O}_{11}$ & $493.1714,987.3504,415.1223$ & $\begin{array}{l}\text { Methylalbiflorin } \\
\text { Hydrolysis reaction of } \\
\text { echinacoside }\end{array}$ \\
P29 & 8.713 & 623.1995 & 623.1976 & 3 & $\mathrm{C}_{29} \mathrm{H}_{36} \mathrm{O}_{15}$ & $623.1995,459.1286,295.0597$ & $\begin{array}{l}\text { PL } \\
\text { CH }\end{array}$ \\
M22 & 9.213 & 317.1025 & 317.1018 & -2.2 & $\mathrm{C}_{17} \mathrm{H}_{18} \mathrm{O}_{6}$ & $317.1025,363.1080,299.0919$ & Albiflorinaglycone \\
M23 & 9.296 & 509.1653 & 509.1659 & -1.2 & $\mathrm{C}_{24} \mathrm{H}_{30} \mathrm{O}_{12}$ & $509.1653,491.1569,479.1538$ & Methyloxyalbiflorin \\
P30 & 9.306 & 283.2645 & 283.2637 & 2.8 & $\mathrm{C}_{18} \mathrm{H}_{36} \mathrm{O}_{2}$ & $283.2645,329.2692,269.2475$ & Octadecanoic acid \\
M24 & 9.666 & 447.0939 & 447.0927 & 2.7 & $\mathrm{C}_{21} \mathrm{H}_{18} \mathrm{O}_{11}$ & $447.0939,429.0823,411.0716$ & Genistein-O-glucuronide & PL \\
M25 & 9.670 & 477.0678 & 477.0669 & 1.9 & $\mathrm{C}_{21} \mathrm{H}_{18} \mathrm{O}_{13}$ & $477.0678,283.0447,523.0721$ & Quercetin-O-glucuronide & UR \\
P31 & 10.590 & 297.0409 & 297.0399 & 3.4 & $\mathrm{C}_{16} \mathrm{H}_{10} \mathrm{O}_{6}$ & $297.409,343.0437$ & LR & Irilone \\
M26 & 10.846 & 209.0820 & 209.0814 & 2.9 & $\mathrm{C}_{11} \mathrm{H}_{12} \mathrm{O}_{4}$ & $289.0820,178.0625,191.0702$ & Methylferulic acid & UR \\
P32 & 11.253 & 1073.5540 & 1073.5532 & 0.7 & $\mathrm{C}_{53} \mathrm{H}_{86} \mathrm{O}_{22}$ & $1073.5540,1119.5554,749.4459$ & Macranthoside \\
P33 & 12.110 & 413.3788 & 413.3783 & 1.2 & $\mathrm{C}_{29} \mathrm{H}_{48} \mathrm{O}$ & $413.3788,367.3365,301.2516$ & Sitosterol/isomer \\
P34 & 12.170 & 749.4482 & 749.4476 & 0.8 & $\mathrm{C}_{41} \mathrm{H}_{66} \mathrm{O}_{12}$ & $751.4638,795.4532,603.3890$ & Kalopanaxsaponin A \\
P35 & 12.294 & 313.1818 & 313.1804 & 4.5 & $\mathrm{C}_{20} \mathrm{H}_{26} \mathrm{O}_{3}$ & $313.1818,295.1712,277.1591$ & Oxyphyllacinol \\
M27 & 13.365 & 521.1659 & 521.1635 & -4.6 & $\mathrm{C}_{25} \mathrm{H}_{30} \mathrm{O}_{12}$ & $521.1659,1043.3396$ & LR & UR \\
\hline
\end{tabular}

UR, Uncaria rhynchophylla; CH, Cistanches Herba; PL, Paeonia lactiflora; LR, Linderae Radix; DO, Dioscorea opposite; AO, Alpinia oxyphylla.

\section{Prototypes constituents and metabolites screening of WSYGD in mouse plasma}

\section{Analysis of prototype constituents}

To elucidate the MS/MS information of the exogenous using UPLC-ESI-Q-TOF-MS technique, a comprehensive comprehending of retention regularities and changes in mass spectra of the prototype constituents is essential. Combined the exact mass $<5.0 \mathrm{ppm}$, the composition of elemental can be explicit acknowledged. By analyzing their accurate mass and MS fragment pathways along with the available literature, 97 prototype ingredients were identified. Taken the compound of P13 as an example, $\mathrm{P} 13$ had a molecular ion $[\mathrm{M}-\mathrm{H}]^{-}$at $\mathrm{m} / \mathrm{z} 314.1393$ and produce fragmentation with the peak at $\mathrm{m} / \mathrm{z} 298.1083$ [M$\left.\mathrm{H}^{-\mathrm{CH}_{4}}\right]^{-}, 286.1445$ [M-H-CO]', 282.1133 [M-H-CH $3^{-}$ $\mathrm{OH}]^{-}, \quad 270.1135 \quad\left[\mathrm{M}-\mathrm{H}_{-} \mathrm{CH}_{4}-\mathrm{CO}\right]^{-}, \quad 256.1348$ $\left[\mathrm{M}-\mathrm{H}-\mathrm{C}_{2} \mathrm{H}_{3} \mathrm{O}_{2}\right]^{-}, \quad 192.1022 \quad\left[\mathrm{M}-\mathrm{H}-\mathrm{C}_{7} \mathrm{H}_{6} \mathrm{O}_{2}\right]^{-}$. The chemical formula of $\mathrm{P} 13$ was conjectured to be $\mathrm{C}_{18} \mathrm{H}_{21} \mathrm{NO}_{4}$ based on the elemental composition, unsaturation degree and relative abundance. Therefore, ion P13 was deduced preliminarily as Coclaurine (Figure 7).

\section{Characterization of mouse metabolites of WSYGD}

The total ion chromatogram of the endogenous and exogenous compounds in plasma after oral administration of WSYGD was analyzed by the software of Metabolynx 4.1 (Supplementary Figure 2). The possible metabolic pathway of major compounds is indicated in Figure 8. Most of the metabolites remained the skeleton structural characteristics which absorbed in blood [17], the study of fragmentation pathways accelerated the authentication of metabolites from WSYGD in plasma.

The retention time of M9 chromatographic peak was $5.050 \mathrm{~min}$ with the $[\mathrm{M}-\mathrm{H}]^{-}$ion at $\mathrm{m} / \mathrm{z} 199.0970$ and the characterized molecular ion at $\mathrm{m} / \mathrm{z} 151.1002,123.0988$, 108.0978, and the fragmentation behavior was confirmed in accordance with previous literature [18]. Simultaneously, M1 was found on RT 0.402 minute with the ion of $[\mathrm{M}+\mathrm{H}]{ }^{+}$at $\mathrm{m} / \mathrm{z}$ 201.1120. Therefore, M9 and M1 were identified as Paeonimetabolin I and Paeonimetabolin II.

Metabolite M2 exhibited the ion of $[\mathrm{M}-\mathrm{H}]^{-}$at $\mathrm{m} / \mathrm{z}$ 297.0616 and was obtained at 0.720 minute. The chemical formula of $\mathrm{M} 2$ was $\mathrm{C}_{13} \mathrm{H}_{14} \mathrm{O}_{8}$, which was 176 Da higher than that of benzoic acid and exhibited the fragmentation of 121.0132 [M-GluA] ${ }^{+}$. M2 was tentatively assigned as glucuronidated product of Benzoic acid-O-glucuronide.

Metabolites M14 ( $t_{R}=1.35$ min) showed the ion of [M$\mathrm{H}]^{-}$at $\mathrm{m} / \mathrm{z}$ 375.1291, which the molecular formula was calculated to be $\mathrm{C}_{16} \mathrm{H}_{24} \mathrm{O}_{10}$. The fragment ion which produced by $[\mathrm{M}-\mathrm{H}]^{-}$was exhibited at 375.1291 [M$\left.\mathrm{C}_{7} \mathrm{H}_{4} \mathrm{O}\right]^{-}$. Simultaneously, it was $104 \mathrm{Da}$ lower than paeoniflorin, and the characterized fragment ion at $\mathrm{m} / \mathrm{z}$ 345.1186, 327.1124, 283.1115. Ultimately, M14 [19] was tentatively identified as desbenzoylpaeoniflorin. Metabolite M6 was detected on the Rt $2.51 \mathrm{~min}$ of chromatogram and produced an ion of $[\mathrm{M}-\mathrm{H}]^{-}$at $\mathrm{m} / \mathrm{z}$ $507.1758\left(\mathrm{C}_{21} \mathrm{H}_{32} \mathrm{O}_{14}\right)$, which was $132 \mathrm{Da}\left(\mathrm{C}_{6} \mathrm{H}_{8} \mathrm{O}_{6}\right.$ $\mathrm{CO}_{2}$ ) higher than desbenzoylpaeoniflorin, indicating that the ingredients were conjugated with glucuronic acid, happening phase II in metabolic processes. Simultaneously, the main products ion of 327.1046, $283.1035,165.1022,121.1049$ was present based on the fragmentation pattern. Therefore, M6 was designated as desbenzoyl product of paeoniflorin-O-glucuronide. Metabolite M11 $\left(\mathrm{t}_{\mathrm{R}}=5.53 \mathrm{~min}\right)$ presented an ion of [M$\mathrm{H}]^{-}$at $\mathrm{m} / \mathrm{z} 449.1440\left(\mathrm{C}_{17} \mathrm{H}_{24} \mathrm{O}_{10}\right)$. Therefore, M5 and M11 were designated as demethylene hydroxyl oxypaeoniflorin, demethylene hydroxyl paeoniflorin. M26 exhibited quasi-molecular $[\mathrm{M}-\mathrm{H}]^{-}$ion at $\mathrm{m} / \mathrm{z}$ 521.1659 and the chemical formula calculated to be $\mathrm{C}_{25} \mathrm{H}_{30} \mathrm{O}_{12}$, which was $42 \mathrm{Da}$ lower than paeoniflorin. M26 was identified as acetylation paeoniflorin. 

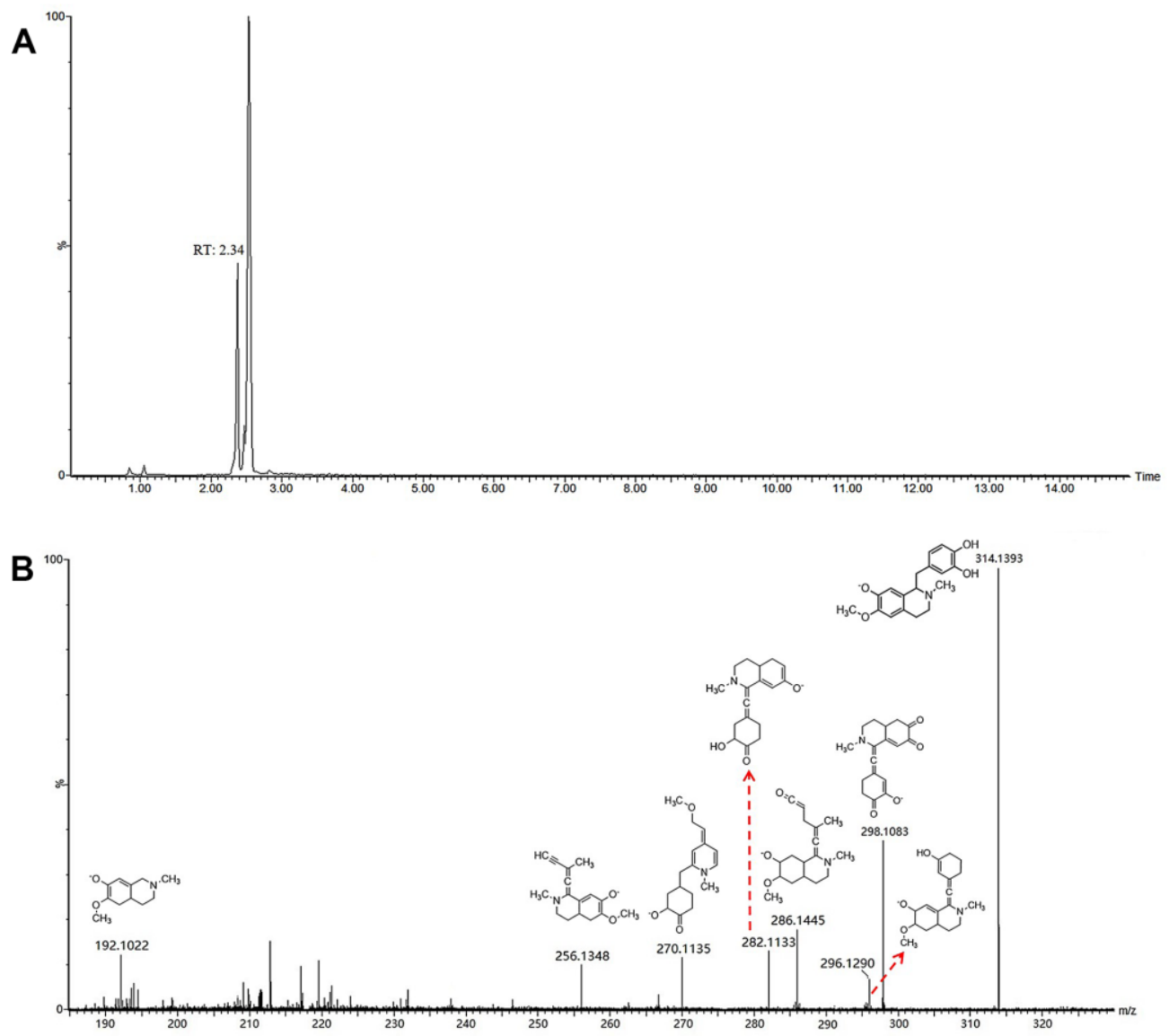

Figure 7. Chromatograms (A) and fragmentations and mode assignments (B) of coclaurine.
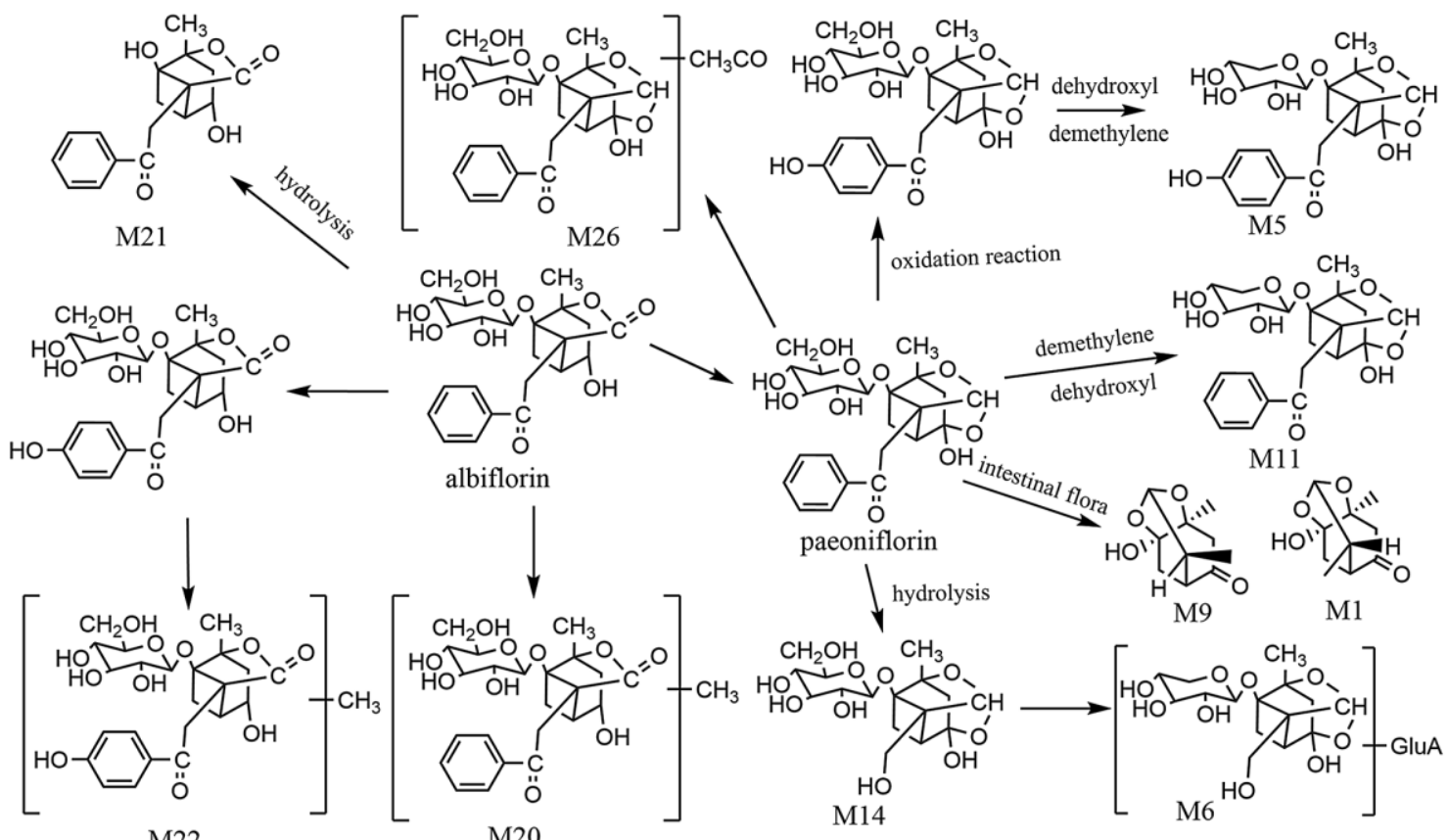

M22

Figure 8. The proposed metabolic profiles of paeoniflorin-related metabolites. 
Table 2. Statistical results of linear regression equation analysis in the determination of main compounds.

\begin{tabular}{|c|c|c|c|c|c|c|}
\hline Analyte & Regression equation & $r^{2}$ & $\operatorname{LOD}(\mu \mathrm{g} / \mathrm{mL})$ & $\mathrm{LOQ}(\mu \mathrm{g} / \mathrm{mL})$ & Linear range $(\mu \mathrm{g} / \mathrm{mL})$ & $\operatorname{content}(\mu \mathrm{g} / \mathrm{g})$ \\
\hline Geniposidic acid & $\mathrm{Y}=530.4614 \mathrm{X}+560.4806$ & 0.9996 & 0.082 & 0.280 & $25.67-256.7$ & 35.45 \\
\hline Coclaurine & $Y=497.2478 X-286.269$ & 0.9993 & 0.095 & 0.225 & $19.97-199.7$ & 26.08 \\
\hline Nootkatone & $Y=59913.3219 X+160.8017$ & 0.9992 & 0.115 & 0.378 & $15.25-152.5$ & 18.93 \\
\hline Rutin & $Y=3200.4089 X+99.2290$ & 0.9994 & 0.078 & 0.215 & $27.2-870$ & 120.35 \\
\hline Paeoniflorin & $Y=321.0675 X+135.5458$ & 0.9998 & 0.065 & 0.546 & $26.78-267.8$ & 98.58 \\
\hline Linderane & $Y=3269.2578 X+4578.7369$ & 0.9999 & 0.108 & 0.376 & $1.64-16.4$ & 3.67 \\
\hline Quercetin & $Y=5365.7657 X-7.6742$ & 0.9999 & 0.105 & 0.256 & $1.02-15.2$ & 1.23 \\
\hline
\end{tabular}

Paeoniflorin was easy isomerize into albiflorin, and the intensity of the peaks is different. M20 had an $[\mathrm{M}-\mathrm{H}]^{-}$ ion at $\mathrm{m} / \mathrm{z} 493.1714\left(\mathrm{C}_{24} \mathrm{H}_{30} \mathrm{O}_{11}\right)$, which was $15 \mathrm{Da}$ higher than albiflorin. M22 emerged an ion of $[\mathrm{M}-\mathrm{H}]^{-}$at $\mathrm{m} / \mathrm{z} \quad 317.1025\left(\mathrm{C}_{17} \mathrm{H}_{18} \mathrm{O}_{6}\right)$ and 30 Da more than albiflorin. Therefore, M20 and M22 were identified as methylalbiflorin and methyloxyalbiflorin. Metabolite M21 exhibited the ion of $[\mathrm{M}-\mathrm{H}]^{-}$at $\mathrm{m} / \mathrm{z} 317.1025$ $\left(\mathrm{C}_{17} \mathrm{H}_{18} \mathrm{O}_{6}\right)$, which was $162 \mathrm{Da}$ higher than that of albiflorin. It was indicating that the constituent was obtained through the loss of glycoside group. M21 was designated as albiflorinaglycone.

$\mathrm{M} 11\left(\mathrm{t}_{\mathrm{R}} 5.62 \mathrm{~min}\right)$ and $\mathrm{M} 16\left(\mathrm{t}_{\mathrm{R}} 6.56 \mathrm{~min}\right)$ emerged the ions of $[\mathrm{M}+\mathrm{H}]^{+}$at $\mathrm{m} / \mathrm{z} 399.1950$ and 399.1911, respectively. Simultaneously, the chemical of M11 and M16 have the same molecular formula, $\mathrm{C}_{22} \mathrm{H}_{26} \mathrm{~N}_{2} \mathrm{O}_{5}$, and were $16 \mathrm{Da}$ more than that of isocorynoxeine. M11 and M16 were acknowledged as isocorynoxeine-Noxide and corynoxeine- $\mathrm{N}$-oxide based on the reserve time, exact mass and diagnostic fragment ions [20]. The other metabolites, such as M2, M3, M4, M7, M8, M10, M12, M13, M15, M17, M18, M19, M23, M24, M25, were identified using the same methods.

\section{Quantification of ten main constituents in WSYGD}

The correlation coefficient $\left(\mathrm{r}^{2}\right)$ of the calibration curve > 0.999 , indicating good linearity. The LOD, LOQ, intraand inter day precision, repeatability, and recoveries were tested and the obtained results were summarized in Tables 2, 3, demonstrating good repeatability for the simultaneous quantification of the ten main constituents in WSYGD. Their typical chromatograms were shown in Figure 9.

\section{CONCLUSIONS}

Parkinson disease, the common disabling neurodegenerative disease, was bound up with the loss of dopaminergic neurons in the SN. Proinflammatory mediators was released caused by the microglia activates which associated with injured dopaminergic neurons. Ultimately, it was caused the successive dopaminergic neural degeneration correlative with the aggregated proteins, such as nitrated $\alpha$-syn, of Parkinson disease released. However, it is debatable whether or not WSYGD could make any difference. According to this research, (1) WSYGD could ameliorate the PD behaviors of rotenone-intoxicated mice, down-regulate the expression of $\alpha$-synuclein and refrain from the reduce of $\mathrm{SN}$ dopaminergic neurons; (2) the mice of rotenone-intoxicated had neuroinflammatory symptoms such as raised conveyance of peripheral immune factors, which could be improved by WSYGD. Simultaneously, we developed a dependable method to discriminate the diverse the endogenous and exogenous compounds originate from complicated herbal extracts. Recently, LC-MS/MS, due to its high selectivity, sensitivity and chromatographic resolution, has been utilized for the authentication and quantitation of bioanalysis of complex matrix samples. Therefore, the combine of LC-MS/MS and multivariate statistical analysis was built to research the chemical ingredient and xenobiotics in mice after oral administration of WSYGD. By this means, a total of 97 chemical constituents and 62 metabolites were characterized tentatively. More importantly, 35 prototype constituents and 27 metabolites of WSYGD after oral administration were screened based on the fragmentation behavior of WSYGD in mouse plasma. Simultaneously, quantitative analysis of ten main constituents in WSYGD was replicated. It is still necessary to make further efforts to the biological evaluation and the concrete the characteristics of drug metabolism among the multicomponent. The results will supply one species of rapid and highly efficient method for the authentication of ingredients and the obtained knowledge that might be helpful to guide the clinical applications of these TCM in PD. 
Table 3. Precision, repeatability, and stability data of ten compounds of WSYGD.

\begin{tabular}{|c|c|c|c|c|c|c|c|c|}
\hline \multirow{3}{*}{ Analyte } & \multicolumn{4}{|c|}{ Precision } & \multirow{2}{*}{\multicolumn{2}{|c|}{$\begin{array}{c}\text { Repeatability } \\
(\mathbf{n}=\mathbf{6})\end{array}$}} & \multirow{2}{*}{\multicolumn{2}{|c|}{$\begin{array}{c}\text { Recovery } \\
(\mathbf{n}=\mathbf{6}) \\
\end{array}$}} \\
\hline & \multicolumn{2}{|c|}{$\operatorname{Intraday}(n=6)$} & \multicolumn{2}{|c|}{$\operatorname{Interday}(\mathbf{n}=6)$} & & & & \\
\hline & $\operatorname{Mean}(\mu \mathrm{g} / \mathrm{g})$ & $\operatorname{RSD}(\%)$ & $\operatorname{Mean}(\mu \mathrm{g} / \mathrm{g})$ & $\operatorname{RSD}(\%)$ & $\operatorname{Mean}(\mu \mathrm{g} / \mathrm{g})$ & $\operatorname{RSD}(\%)$ & $\operatorname{Mean}(\%)$ & $\operatorname{RSD}(\%)$ \\
\hline Geniposidic acid & 37.25 & 2.52 & 36.13 & 1.85 & 33.38 & 2.34 & 98.98 & 1.87 \\
\hline Coclaurine & 25.57 & 1.56 & 25.12 & 2.26 & 27.13 & 2.78 & 102.58 & 2.90 \\
\hline Rhynchophylline & 23.76 & 2.03 & 25.30 & 1.80 & 26.09 & 1.86 & 99.07 & 1.84 \\
\hline Nootkatone & 18.58 & 2.05 & 19.09 & 2.56 & 18.39 & 2.68 & 104.10 & 1.76 \\
\hline Rutin & 120.34 & 1.97 & 123.47 & 2.80 & 120.56 & 2.98 & 102.67 & 1.08 \\
\hline Echinacoside & 45.89 & 2.65 & 46.27 & 1.85 & 46.07 & 1.24 & 100.05 & 2.37 \\
\hline Acteoside & 55.13 & 2.59 & 57.09 & 2.58 & 55.28 & 2.83 & 102.18 & 2.87 \\
\hline Paeoniflorin & 98.03 & 1.82 & 99.02 & 2.49 & 98.02 & 1.06 & 98.05 & 1.38 \\
\hline Linderane & 3.68 & 2.97 & 3.98 & 1.09 & 3.12 & 1.96 & 103.08 & 2.09 \\
\hline Quercetin & 1.24 & 2.01 & 1.12 & 2.78 & 1.29 & 2.03 & 101.50 & 2.37 \\
\hline
\end{tabular}
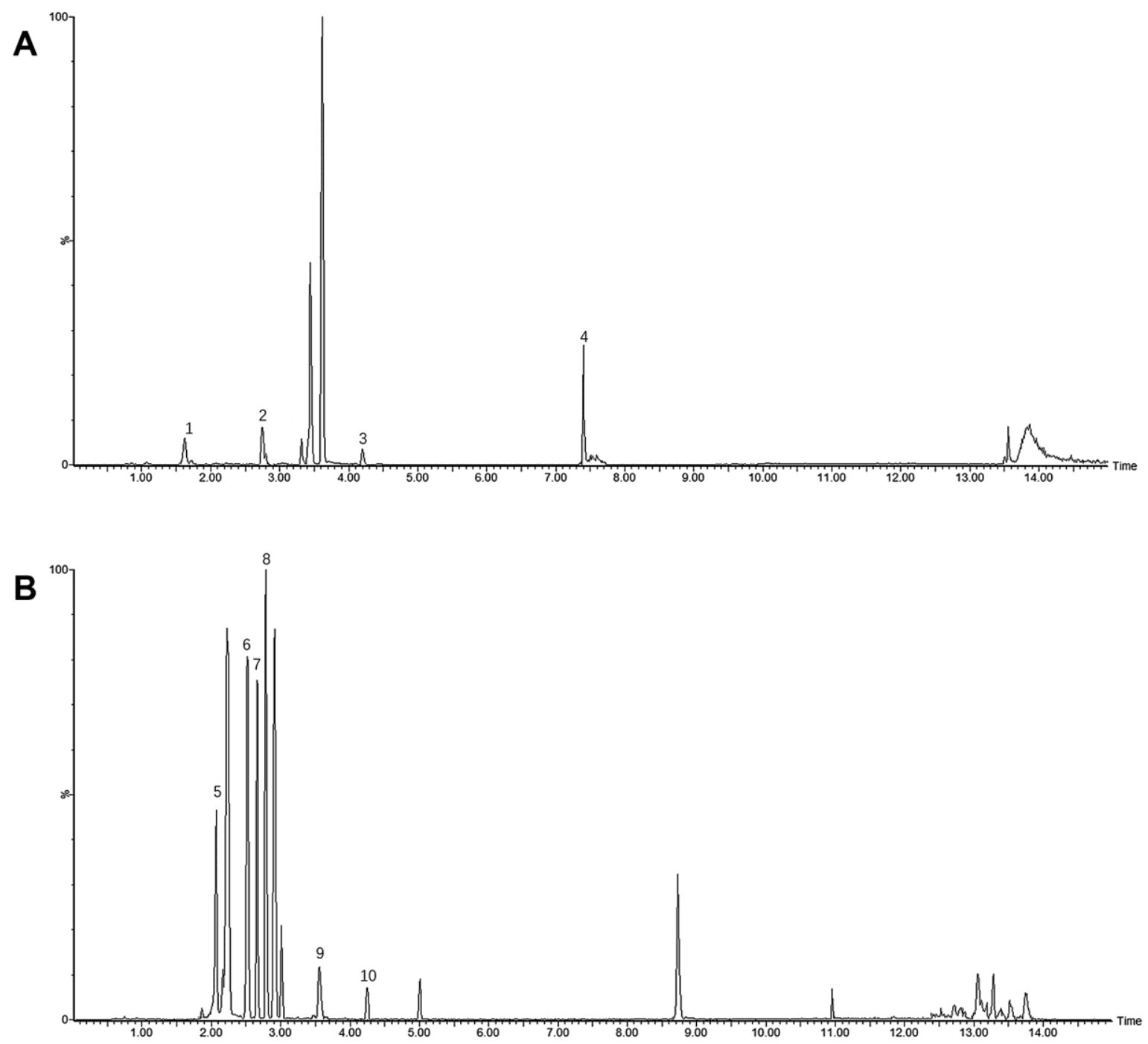

Figure 9. UHPLC-MS/MS spectra and their structures of ten mixture standard compounds in positive mode (A) (1 Geniposidic acid; 2 Coclaurine; 3 Rhynchophylline; 4 Nootkatone) and negative mode (B) (5 Rutin; 6 Echinacoside; 7 Acteoside; 8 Paeoniflorin; 9 Linderane; 10 Quercetin). 


\section{Abbreviations}

OPLS-DA: Orthogonal partial least squared discriminate analysis; PCA: Principal component analysis; PD: Parkinson's disease; SN: substantia nigra; TCM: Traditional Chinese medicine; WSYGD: WenShen-Yang-Gan decoction; TNF- $\alpha$ : Tumor necrosis factor- $\alpha$; IL-17: interleukin-17; IL-22: interleukin-22; IFN- $\gamma$ : Interferon-gamma; IL-1 $\beta$ : Interleukin- 1 beta; IGF-1: insulin-like growth factors -1 ; TGF- $\beta$ : transforming growth factor-beta.

\section{AUTHOR CONTRIBUTIONS}

G.X. Zhu and Y. Zhao designed the research. W. Wang, C. Chen, L.L. Tang and G.X. Zhu performed the experiments. Y. Liang, Z.N. Zhang, and Yan Lu analyzed the data; G.X. Zhu, W. Wang and Y. Zhao wrote the manuscript. All authors read and approved the final manuscript.

\section{CONFLICTS OF INTEREST}

The authors declare that they have no conflicts of interest.

\section{FUNDING}

Supported by Jiangsu province TCM leading talents project (SLJ0214), National Natural Science Foundation of China (82003933), Nanjing Youth Talent Training Plan of TCM(ZYQ20006), Nanjing medical science and technology development project (YKK20167, ZKKX20050), and Nanjing Chinese Medicine Modernization and Big Data Research Center, Gu Xiaosong's Academician Workstation.

\section{Editorial note}

${ }^{\&}$ This corresponding author has a verified history of publications using a personal email address for correspondence.

\section{REFERENCES}

1. Poewe W, Seppi K, Tanner CM, Halliday GM, Brundin P, Volkmann J, Schrag AE, Lang AE. Parkinson disease. Nat Rev Dis Primers. 2017; 3:17013. https://doi.org/10.1038/nrdp.2017.13 PMID:28332488

2. Ji GJ, Ren C, Li Y, Sun J, Liu T, Gao Y, Xue D, Shen L, Cheng $\mathrm{W}$, Zhu $C$, Tian $Y$, Hu P, Chen X, Wang K. Regional and network properties of white matter function in Parkinson's disease. Hum Brain Mapp. 2019; 40:1253-63. https://doi.org/10.1002/hbm.24444 PMID:30414340
3. Grünewald A, Kumar KR, Sue CM. New insights into the complex role of mitochondria in Parkinson's disease. Prog Neurobiol. 2019; 177:73-93.

https://doi.org/10.1016/i.pneurobio.2018.09.003 PMID:30219247

4. Chen KY, Wu MY, Yang PS, Chiang JH, Hsu CY, Chen CY, Yen HR. Utilization of Chinese herbal medicine and its association with the risk of fracture in patients with Parkinson's disease in Taiwan. J Ethnopharmacol. 2018; 226:168-75. https://doi.org/10.1016/j.jep.2018.08.021 PMID:30118835

5. Elbassuoni EA, Ahmed RF. Mechanism of the neuroprotective effect of GLP-1 in a rat model of Parkinson's with pre-existing diabetes. Neurochem Int. 2019; 131:104583.

https://doi.org/10.1016/i.neuint.2019.104583 PMID:31654678

6. Lai $\mathrm{CY}$, Chiang JH, Lin JG, Yen HR, Tu CH, Chen YH. Chinese herbal medicine reduced the risk of stroke in patients with Parkinson's disease: A population-based retrospective cohort study from Taiwan. PLoS One. 2018; 13:e0203473.

https://doi.org/10.1371/journal.pone.0203473 PMID:30192890

7. Tang LL, Chen C, Lu Y, Liang Y, Tang JJ, Zhao Y. Disease-modifying Effects of Kidney-warming LiverNourishing Prescription in Early Intervention for Constipation on Parkinson's Disease. Western Journal of Traditional Chinese Medicine. 2018; 21:4-7.

8. Chen C, Liang Y, Tang LL, Xia BM, Tang JJ, Lu Y, Zhao Y. A clinical study of 30 cases of non-motor symptoms of Parkinson's disease treated with Wenshenyanggan decoction. Lishizhen Medicine and Materia Medica Research. 2017; 28:636-38.

9. Liang $\mathrm{Y}$, Chen $\mathrm{C}, \mathrm{Xia} \mathrm{B}, \mathrm{Wu} \mathrm{W}$, Tang J, Chen $\mathrm{Q}$, Tang $\mathrm{L}$, Yang $\mathrm{H}$, Zhang Z, Lu Y, Yang $\mathrm{Y}$, Zhao Y. Neuroprotective Effect of Echinacoside in Subacute Mouse Model of Parkinson's Disease. Biomed Res Int. 2019; 2019:4379639.

https://doi.org/10.1155/2019/4379639 PMID:30834264

10. Chen C, Xia B, Tang L, Wu W, Tang J, Liang Y, Yang H, Zhang Z, Lu Y, Chen G, Yang Y, Zhao Y. Echinacoside protects against MPTP/MPP ${ }^{+}$-induced neurotoxicity via regulating autophagy pathway mediated by Sirt1. Metab Brain Dis. 2019; 34:203-12.

https://doi.org/10.1007/s11011-018-0330-3 PMID:30426321

11. Zhu G, Feng F. UPLC-MS-based metabonomic analysis 
of intervention effects of Da-Huang-Xiao-Shi decoction on ANIT-induced cholestasis. J Ethnopharmacol. 2019; 238:111860.

https://doi.org/10.1016/i.jep.2019.111860

PMID: 30965080

12. Wishart DS. Emerging applications of metabolomics in drug discovery and precision medicine. Nat Rev Drug Discov. 2016; 15:473-84.

https://doi.org/10.1038/nrd.2016.32 PMID:26965202

13. Wild CP, Scalbert A, Herceg Z. Measuring the exposome: a powerful basis for evaluating environmental exposures and cancer risk. Environ Mol Mutagen. 2013; 54:480-99.

https://doi.org/10.1002/em.21777

PMID:23681765

14. Houten SM. Metabolomics: unraveling the chemical individuality of common human diseases. Ann Med. 2009; 41:402-07. https://doi.org/10.1080/07853890902729794 PMID:19191053

15. Zhu G, Chen $Y, H u Q$, Zhang $Q$, Lv $Q$, Feng F. Plasma metabolic profiling analysis of normal and ANITinduced cholestasis rats after oral administration of Da-Huang-Xiao-Shi decoction using UHPLC-Q-Orbitrap MS coupled with pattern recognition. Analytical Methods. 2018; 10:4827-37. https://doi.org/10.1039/C8AY01945B

16. King AM, Mullin LG, Wilson ID, Coen M, Rainville PD, Plumb RS, Gethings LA, Maker G, Trengove R. Development of a rapid profiling method for the analysis of polar analytes in urine using HILIC-MS and ion mobility enabled HILIC-MS. Metabolomics. 2019; 15:17. https://doi.org/10.1007/s11306-019-1474-9

PMID:30830424

17. Zhu G, Feng F. Non-targeted metabolite profiling and specific targeted discrimination strategy for quality evaluation of Cortex Phellodendri from different varieties. Rsc Advances. 2018; 8:22086-94. https://doi.org/10.1039/C8RA03369B

18. Akao T, Shu YZ, Matsuda Y, Hattori M, Namba T, Kobashi K. Metabolism of paeoniflorin and related compounds by human intestinal bacteria. IV. Formation and structures of adducts of a metabolic intermediate with sulfhydryl compounds by Lactobacillus brevis. Chem Pharm Bull (Tokyo). 1988; 36:3043-48.

https://doi.org/10.1248/cpb.36.3043 PMID:3240512

19. Lu $M, H u ~ Q$, Zhang $Y$, Zhai $Y$, Zhou $Y$, Jiang J. Comparative chemical profiling of three TCM drugs in the Paeoniaceae family by UPLC-MS/MS combined with chemometric methods. Biochem Syst Ecol. 2019; 83:121-29. https://doi.org/10.1016/j.bse.2019.02.002

20. Zhao L, Qi W, Chen F, Sun J, Yuan D. Metabolic Profile of Isocorynoxeine in Rats Obtained by Ultra-High Performance Liquid Chromatography/Quadrupole Time-of-Flight Mass Spectrometry. Eur J Drug Metab Pharmacokinet. 2016; 41:615-26. https://doi.org/10.1007/s13318-015-0287-0 PMID:26077124 


\section{SUPPLEMENTARY MATERIALS}

\section{Supplementary Figures}

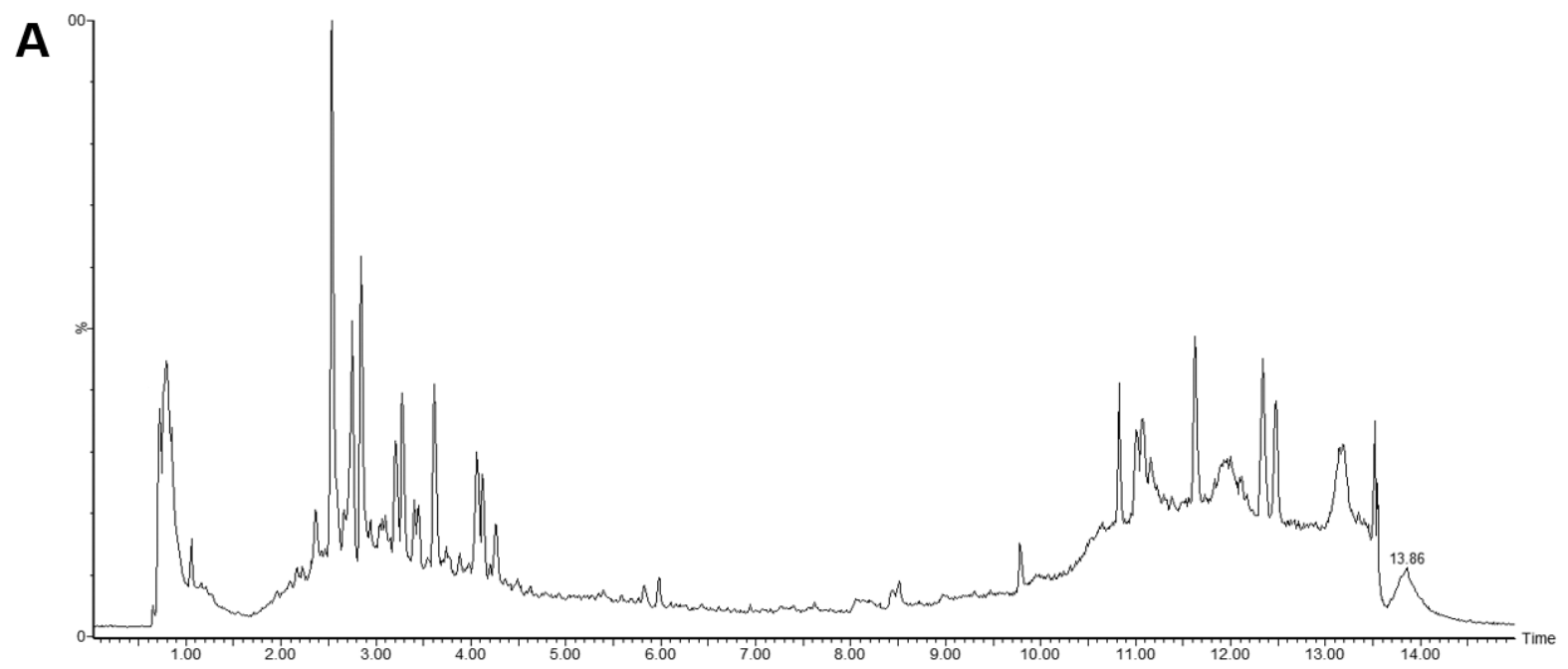

B

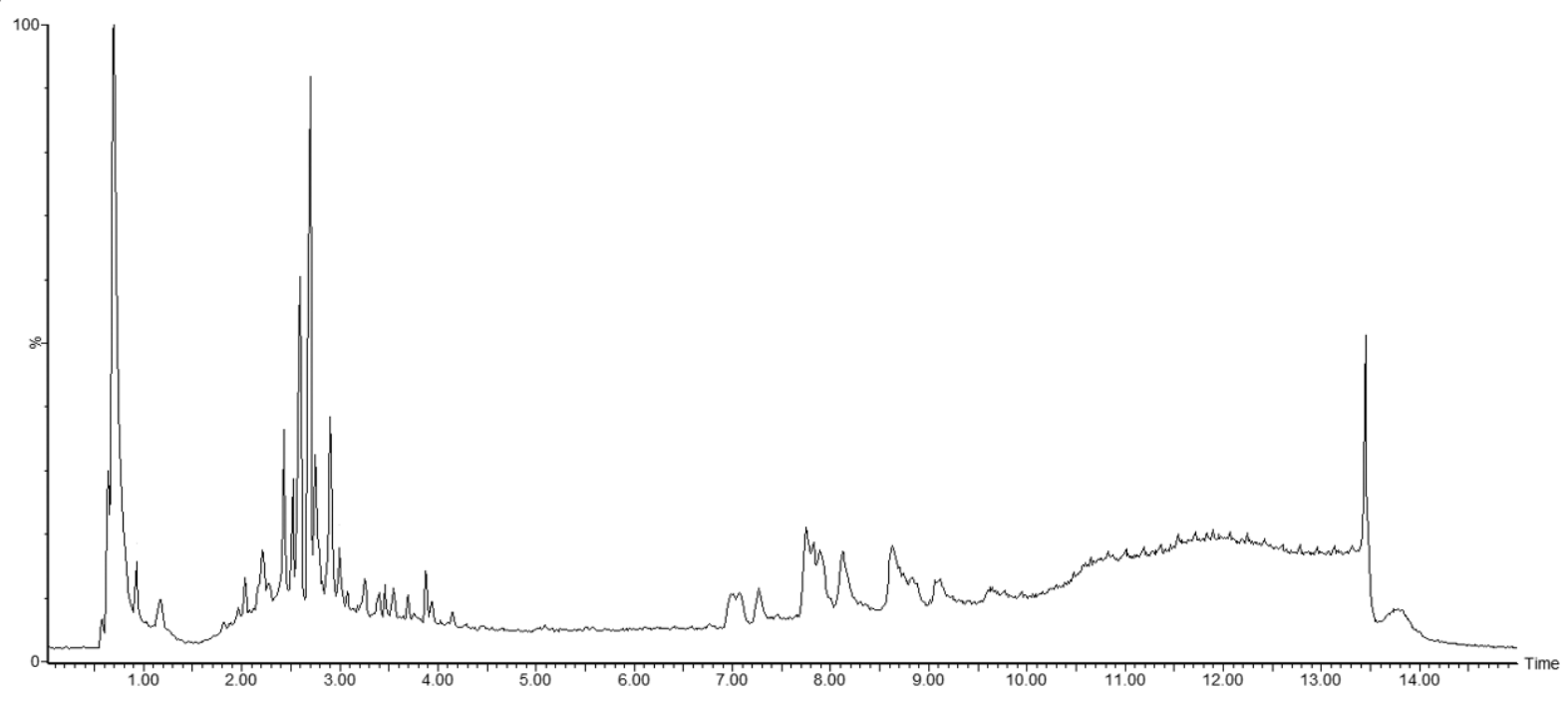

Supplementary Figure 1. The total ion chromatogram of WSYGD extract in positive ion (A) and negative ion (B). 

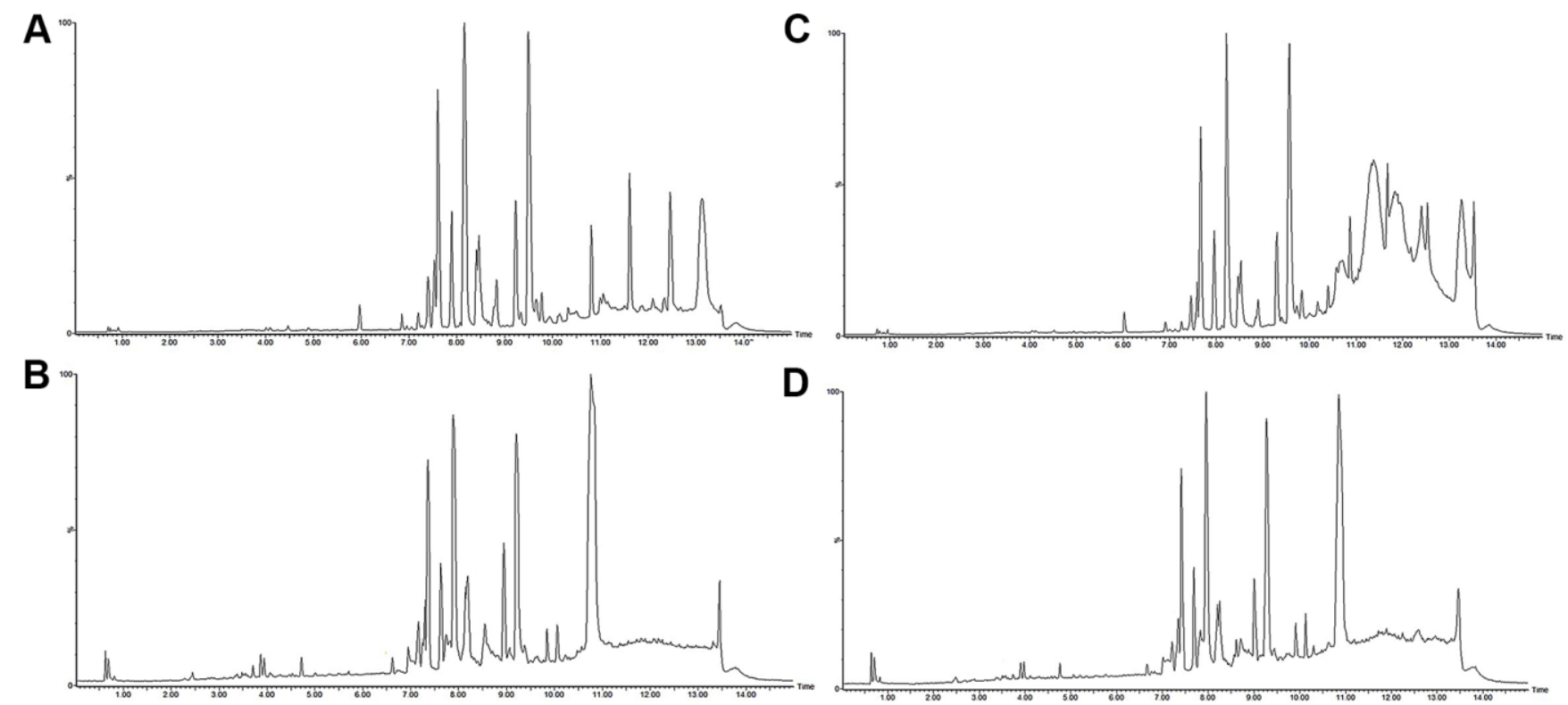

Supplementary Figure 2. Chromatograms of WSYGD in mouse plasma by UPLC-ESI-Q-TOF MS: (A) total ion chromatogram in positive ion mode of blank, (B) total ion chromatogram in negative ion mode of blank, (C) total ion chromatogram in positive ion mode of WSYGD, (D) total ion chromatogram in negative ion mode of WSYGD. 


\section{Supplementary Table}

Please browse Full Text version to see the data of Supplementary Table 1.

Supplementary Table 1. Components identified from Wen-Shen-Yang-Gan decoction. 